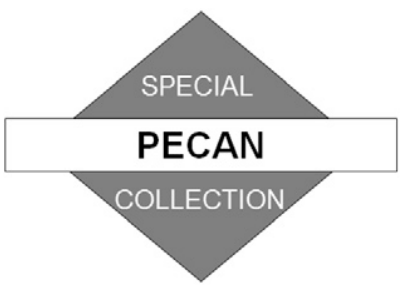

\title{
The Relation between Nocturnal MCS Evolution and Its Outflow Boundaries in the Stable Boundary Layer: An Observational Study of the 15 July 2015 MCS in PECAN
}

\author{
COLTIN GRASMICK AND BART GEERTS \\ Department of Atmospheric Sciences, University of Wyoming, Laramie, Wyoming \\ DAVID D. TURNER \\ NOAA/Earth System Research Laboratory/Global Systems Division, Boulder, Colorado \\ ZHIEN WANG \\ Department of Atmospheric Sciences, University of Wyoming, Laramie, Wyoming \\ T. M. WECKWERTH \\ Earth Observing Laboratory, National Center for Atmospheric Research, Boulder, Colorado
}

(Manuscript received 10 May 2018, in final form 4 August 2018)

\begin{abstract}
The vertical structures of a leading outflow boundary ahead of a continental nocturnal MCS and of the upstream environment are examined in order to answer the question of whether this vertical structure affects new cell formation and thus MCS maintenance. The MCS in question, observed on 15 July 2015 as part of the Plains Elevated Convection at Night (PECAN) experiment, formed near sunset as a surface-based, density current-driven system. As the night progressed and a stable boundary layer developed, convection became elevated, multiple fine lines became apparent (indicative of an undular bore), and convection increasingly lagged the outflow boundary. Bore-like boundaries became most apparent where the outflow boundary was oriented more perpendicular to the low-level jet, and the lower troposphere was more susceptible to wave trapping. This case study uses a rich array of radiosonde data, as well as airborne Raman lidar and groundbased interferometer data, to profile the temperature and humidity in the lower troposphere. In all soundings, the lifting of air in the residual mixed layer over a depth corresponding to the Raman lidar observed vertical displacement reduced CIN to near zero and enabled deep convection, even though most unstable CAPE steadily decreased during the evolution of this MCS. Both types of outflow boundaries (density currents and bores) initiated convection that helped maintain the MCS. In the case of density currents, cold pool depth and wind shear determined new cell formation and thus MCS maintenance. For bore-like boundaries, bore transformation and propagation were additional factors that determined whether convection initiated and whether it contributed to the MCS or remained separated.
\end{abstract}

\section{Introduction}

Mesoscale convective systems (MCSs) are key to explaining the nighttime maximum in warm season precipitation in the Great Plains of the United States (Maddox 1980; Colman 1990; Carbone et al. 2002). It is important to accurately forecast these MCSs due to the impact of MCS precipitation on agricultural operations

Corresponding author: Bart Geerts, geerts@uwyo.edu and because of the severe weather that these storms often cause. Yet, the quantitative precipitation forecast accuracy for nocturnal MCSs is remarkably low, compared to that for stratiform frontal systems (Clark 2017; Surcel et al. 2017). Models with slightly different initial conditions or physics choices may produce vastly different MCSs (Stensrud et al. 2000; Morrison et al. 2009; Duda et al. 2014). MCS structure and evolution appear to be highly sensitive to ambient conditions during the transition from less-organized afternoon convection-which 
is typically surface based and derives its convective energy from the solar-heated surface and a well-mixed, deep planetary boundary layer (PBL) - to elevated nocturnal convection, which typically organizes at larger scales as the nocturnal stable boundary layer (SBL) deepens, and a low-level jet (LLJ) develops above the SBL (Corfidi et al. 2008; Carbone and Tuttle 2008; Reif and Bluestein 2017).

Convective cells develop when a parcel of air is lofted to its level of free convection (LFC), becoming buoyant with respect to its surrounding environment. Convective cells often initiate in the proximity of deep convection as a result of the lift over convectively cooled outflows impinging on a potentially unstable boundary layer, under a suitable low-level wind profile (Weisman and Rotunno 2004). Here, the focus is on "secondary" convection initiation $(\mathrm{CI})$, which serves to maintain the MCS and propagate it in the direction of the environmental shear. This is in contrast with "pristine" CI, which does not arise under the influence of preexisting convection nearby. When the surface layer air has no convective available potential energy (CAPE), or less CAPE than layers higher up, and the effective inflow layer feeding convective cells is elevated, this initiation is referred to as elevated CI (Glickman 2000).

Several observational studies have documented secondary CI along convective outflow boundaries of nocturnal MCSs. During the daytime, and often also at night, these boundaries behave as density currents (DCs; e.g., Weckwerth and Wakimoto 1992). These boundaries may evolve into bores and solitons (e.g., Kingsmill and Crook 2003; Marsham et al. 2011; White and Helfrich 2014) in the presence of an SBL and a suitable wind profile, as discussed below. Density currents, undular bores, and solitons impinging on an SBL all may support ascent on a scale larger and deeper than that of thermals in the daytime convective PBL, thus enabling CI. For example, Coleman and Knupp (2011) used surface profiling instruments to document the passage of an undular bore and a solitary wave, finding that the wave passage reduced convective inhibition (CIN) and lowered the LFC, making CI more likely. However, other studies (e.g., Toms et al. 2017) have shown that propagating bores may lift parcels to their lifting condensation level (LCL) without producing CI. Thus, a better understanding of the mechanisms and conditions when these propagating wave structures trigger $\mathrm{CI}$ is needed.

The present study analyzes nocturnal, elevated CI near an MCS outflow boundary during the night of 15 July 2015 in western Kansas as part of the Plains Elevated Convection at Night (PECAN) field campaign (Geerts et al. 2017). This MCS propagated forward (to the east) relatively rapidly, faster than the deep-layer mean westerly flow. Such MCS motion commonly occurs from discrete propagation (Bodine and Rasmussen 2017), during which the MCS merges with new convective cells triggered by cold pool or gravity wave forcing (Crook and Moncrieff 1988; Corfidi 2003; Fovell et al. 2006). Periods of discrete propagation can yield rapid convective growth at the leading edge of the convective line, which can surge ahead of other parts of the MCS.

Convective cells continuously formed along some parts of this leading boundary, visible on radar as a well-defined fine line. However, along other sections of this boundary, secondary CI was delayed until well after the passage of the fine line. Recently, Bodine and Rasmussen (2017) investigated another MCS during PECAN to determine possible mechanisms accelerating the leading convective line. Their study predominantly focused on internal factors such as microphysics and kinematics within the storm and their effects on downdraft velocities, hydrometeor loading, and evaporation efficiency; all of these factors strengthen cold pools and promote forward surging.

The present case study similarly investigates storm propagation but focuses on the characteristics of the MCS outflow boundary and the depth and location of vertical air displacements needed for new cell formation. Quasi-instantaneous airborne transects of lidar measurements are especially useful to estimate actual vertical displacements of parcels or layers. These displacements will be compared against the minimum displacement needed to release actual or potential instability. Such an analysis will yield insight into the delayed CI in certain sections along the MCS's leading line. Additional analyses of ground-based in situ and profiling instruments, along with soundings and radar data, will be used to describe the vertical structure of the SBL and the outflow boundary.

The objective of this paper is to examine in a case study how the vertical structure of the environment and outflow boundaries of nocturnal MCSs may affect secondary CI and thus MCS evolution. Section 2 offers a brief background on nocturnal secondary CI mechanisms and the dynamics of a density current impinging on an SBL. Section 3 describes the data and instrumentation used in this case study. Sections 4 and 5 survey the 15 July 2015 MCS, the outflow boundary, the SBL, and CI. Section 6 provides a unique look into the thermodynamic changes upon passage of a density current or bore. We close with sections offering a discussion and a summary.

\section{Background}

The power spectrum of turbulent kinetic energy (TKE) in the daytime convective BL heated from below 


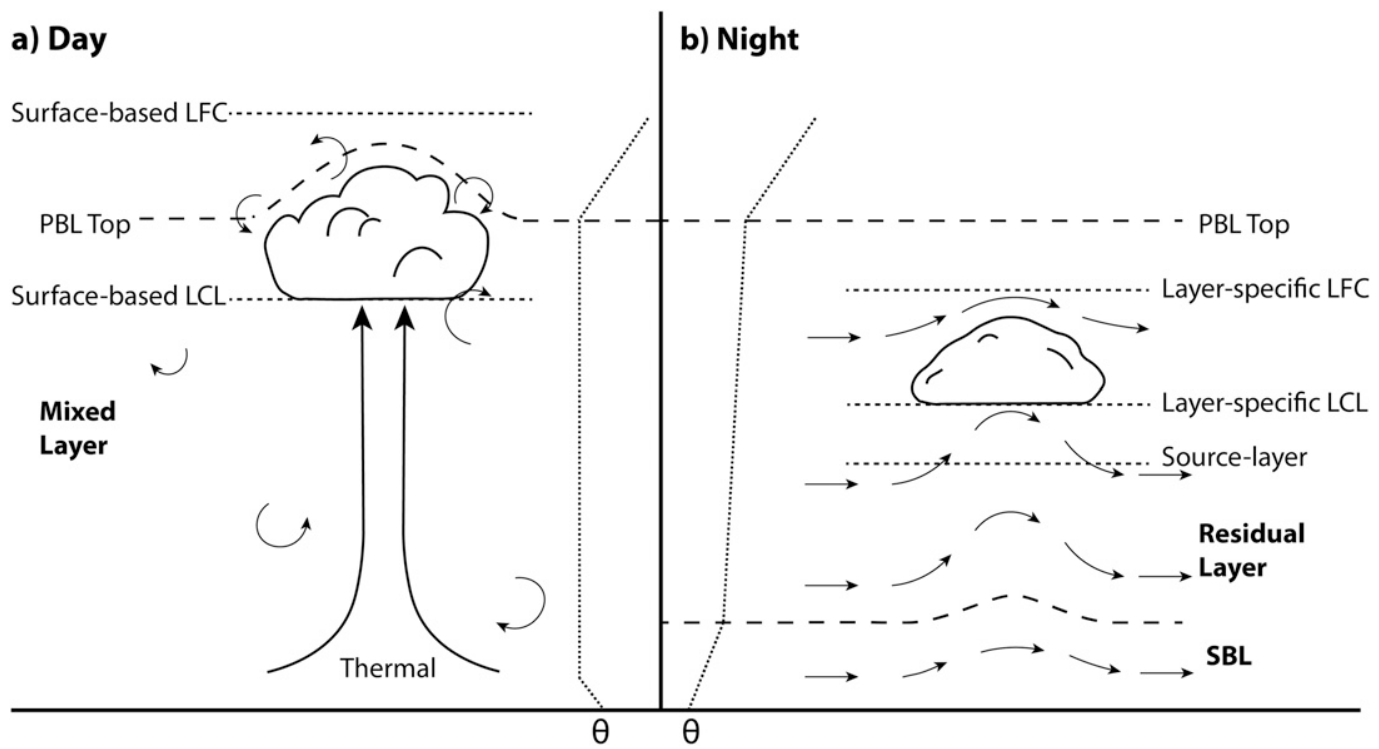

FIG. 1. Diagram contrasting the behavior of typical BL flow in the day and night. Daytime thermal width scales with BL depth. Increasing stability at night promotes laminar flow.

assumes a known distribution in the inertial subrange (Kaimal et al. 1976; Caughey and Palmer 1979). The vertical velocity spectrum in such BL implies that only small eddies will have sufficient TKE to rise to the LFC and that larger, more coherent eddies lack that energy (e.g., Højstrup 1982) unless a persistent circulation is present, like in the case of horizontal convective rolls (Weckwerth 2000). Even relatively small eddies that do rise beyond the LCL, and thus become cumulus clouds, tend to dissipate quickly by entrainment (Paluch and Baumgardner 1989). Thus, CI in the convective PBL typically occurs when the well-mixed air mass is deepened locally by convergent flow, either barotropically (no density gradient) or, more commonly, solenoidally (e.g., Miao and Geerts 2007). A solenoidal, convergent circulation forms in the presence of mesoscale density (or virtual potential temperature) differences in the convective PBL (Markowski and Richardson 2010, chapter 5.3).

When an SBL develops at night, the flow becomes stratified, and the TKE is generally much lower, as illustrated in Fig. 1. A residual well-mixed layer is typically present above the SBL, but turbulent eddies are weak and hardly intrude into the top of the residual mixed layer. Thus, $\mathrm{CI}$ is only possible through local layer lifting to the source-level-specific LFC, over a sufficient width for towering cumulus to survive dissipation by entrainment across the layers of positive CAPE. The question then is what causes this lifting.

Upon reaching the ground, a convective downdraft spreads out, and the leading edge of the convective cold pool behaves as a density current whose speed depends on the cold pool depth and strength, which in turn depend on the ambient profiles of temperature and humidity (Rotunno et al. 1988; James et al. 2006). The cold pool depth and strength generally are related to the subcloud dewpoint depression, the intensity of the parent storm, and the source of downdraft air (entrained midlevel air with low $\theta_{e}$ produces cooler cold pools). Unless the nocturnal SBL is unusually deep and strong and the downdraft CAPE (DCAPE) remains above the surface, the convectively cooled air mixes out down to the ground, and the density current will intrude into the SBL. The interface of such intrusion can assume the structure of a density current, a bore, or a soliton, depending on the cold pool depth, SBL depth, and differences in densities (Rottman and Simpson 1989; Haghi et al. 2017). It has long been established that air lifted over a density current can initiate deep convection (e.g., Mahoney 1988; Weckwerth and Wakimoto 1992). The ability of a density current to trigger deep convection depends on its depth, strength, and the ambient wind profile (Rotunno et al. 1988; Weisman and Rotunno 2004). This is in addition to a moist PBL and midtroposphere to sustain convection and reduce entrainment effects on buoyancy. More recent observational and numerical studies have confirmed that vertical displacements associated with bores and solitons can also initiate deep convection (Koch and Clark 1999; Wilson and Roberts 2006) and maintain MCSs (Parker 2008; Blake et al. 2017).

A bore is a type of hydraulic jump that (unlike a density current) does not transport mass (Kingsmill 
and Crook 2003; Rottman and Simpson 1989). In a hydraulic jump, an abrupt rise in a fluid surface coincides with a change from a region of supercritical fluid velocity to much lower, subcritical velocity. An intrusive density current that is partially blocked by an SBL may produce a bore moving ahead of the density current [e.g., Fig. 1 in Locatelli et al. (1998)]. The nonlinear development of a bore often initiates another type of gravity wave, referred to as a solitary wave, which forms at the head of the bore and propagates at a speed determined by its amplitude (Christie 1989). Typically, multiple solitary waves develop in sequence and appear as an amplitudeordered group of waves, referred to as a soliton (e.g., Knupp 2006).

An unambiguous distinction of the passage of an outflow boundary as a density current, bore, or soliton from radar reflectivity maps and surface observations alone is difficult (Haghi et al. 2017). A density current appears as a single radar "fine line," while an undular bore usually reveals multiple parallel fine lines from additional regions of convergence along solitary waves. The passage of a density current is accompanied by a sudden wind shift in the direction of the fine line movement, a drop in temperature, and a pressure jump (Charba 1974). In contrast, substantial surface cooling may not occur with the passage of a bore. Slight surface warming may even occur due to mixing of the SBL and warmer air aloft descending to the surface. Even so, adiabatic ascent causes net column cooling and a sustained rise in surface pressure (Koch et al. 1991, 2008b). Solitary waves remain unseen in surface observations because they are an elevated gravity wave. High-amplitude oscillations of the SBL top can cause oscillations in surface pressure (Simpson 1987), but solitary waves do not cause a notable wind shift or change in temperature like density currents and bores (Knupp 2006).

Vertical structure information is needed for a more definitive distinction of boundary type, for further bore characterization, and to observe if parcels are lifted to their LFCs (Koch and Clark 1999). Surface-based profiling instruments measuring wind, aerosol layers, humidity, or temperature can describe the vertical displacements in a passing bore (e.g., Demoz et al. 2005; Toms et al. 2017). However, bores may evolve rapidly into solitons (e.g., Knupp 2006); thus, time-height transects from stationary profiling instruments may be misleading. Airborne profiling lidars, on the other hand, can provide quasi-instantaneous transects across evolving bores, as were illustrated by Koch et al. (2008b), who used an airborne differential absorption lidar to profile water vapor across a bore/soliton. An aircraft can also detail the vertical parcel displacements evident from aerosol layers and make in situ measurements.
This allows analysis of wave phase relationships and of horizontal density differences across boundaries, a key parameter to understanding bore behavior (Rottman and Simpson 1989). This approach, which was utilized in Mueller et al. (2017), is used in this study as well.

\section{Data and instrumentation}

\section{a. PECAN overview}

The data used here were collected as part of the 2015 PECAN experiment. The principal objective of PECAN was to improve understanding of the nocturnal precipitation maximum by studying interactions between nocturnal MCSs and the low-level environment (SBL and LLJ) in the Great Plains of North America (Geerts et al. 2017). PECAN deployed a large number and variety of platforms, including aircraft, mobile and fixed radars, and mobile and fixed profiling systems, where the latter were organized into the so-called PECAN Integrated Sounding Arrays (PISAs).

\section{b. Airborne instruments}

One of the aircraft deployed in PECAN was the University of Wyoming King Air (UWKA), equipped with a suite of in situ and remote sensing instruments. The in situ variables investigated in this study include air temperature, air pressure, humidity, and wind (horizontal and vertical components). Flight-level winds are computed using a five-hole gust probe through the method described by Brown et al. (1983) and improved using differential GPS measurements of aircraft altitude and 3D velocity (Haimov and Rodi 2013).

Two different lidars were mounted on the UWKA during PECAN_one upward pointing and the other downward pointing-allowing a continuous profile across flight level. The upward-pointing Wyoming Cloud Lidar (WCL) is a compact elastic lidar operating at $355-\mathrm{nm}$ wavelength [see Wang et al. (2009) for more specifications]. The WCL provides profiles of backscattering coefficient and depolarization ratio. Here, we examine the ratio of total (WCL observed) backscattering to the (known) molecular backscattering, called the lidar scattering ratio (LSR). If LSR equals 1, the atmosphere is essentially free of scattering aerosol particles. An LSR value of 2 indicates that aerosol scattering is of the same magnitude as the scattering by atmospheric gases. LSR values are not conserved through vertical motion because hygroscopic aerosols can absorb liquid water as the relative humidity rises and, thus, scatter the lidar beam differently. The complications of hygroscopic growth and decay do not prevent us from tracking visually continuous aerosol scattering layers even if the 
TABLE 1. Surface network of PECAN platforms and their instruments used in this study with the time of the leading outflow boundary passage. See Geerts et al. (2017) for a more complete description of the PISA network.

\begin{tabular}{|c|c|c|}
\hline Platform and location & Instruments used & Outflow boundary passage \\
\hline FP2-Greensburg, KS & $\begin{array}{l}\text { Radiosonde (Vermeesch 2015), AERI (Turner 2016a), surface station } \\
\text { (UCAR/NCAR-Earth Observing Laboratory 2016a) }\end{array}$ & 0744 UTC \\
\hline FP3-Ellis, KS & Radiosonde (Clark 2016), AERI (Turner 2016b), surface station (Clark 2015) & 0602 UTC \\
\hline FP5-Brewster, KS & $\begin{array}{l}\text { Radiosonde (UCAR/NCAR-Earth Observing Laboratory 2016b), AERI } \\
\text { (Turner 2016c), surface station (UCAR/NCAR-Earth Observing } \\
\text { Laboratory 2016d) }\end{array}$ & 0254 UTC \\
\hline MP2-McCook, KS & Radiosonde (Knupp 2015) & 0425 UTC \\
\hline MP3—Scott City, KS & $\begin{array}{l}\text { Radiosonde (Wagner et al. 2016a), AERI (Wagner et al. 2016c), surface } \\
\text { station (Wagner et al. 2016b) }\end{array}$ & 0348 UTC \\
\hline NSSL1-Hays, KS & Radiosonde (Ziegler et al. 2016) & 0623 UTC \\
\hline UWKA & $\begin{array}{l}\text { 1-Hz flight-level data (University of Wyoming-Research Flight Center } \\
\text { 2017a), CRL (Wang et al. 2016), WCL (UWRFC 2017b) }\end{array}$ & - \\
\hline S-Pol- $38.55^{\circ} \mathrm{N}, 99.54^{\circ} \mathrm{E}$ & $\begin{array}{l}\text { S/Ka-band dual polarization dual wavelength Doppler radar (UCAR/ } \\
\text { NCAR-Earth Observing Laboratory 2016c) }\end{array}$ & 0618 UTC \\
\hline
\end{tabular}

LSR values are not conserved and, by doing so, estimate vertical displacement. The downward-pointing compact Raman lidar (CRL) is a multichannel rotational Raman lidar also operating at $355 \mathrm{~nm}$ (Liu et al. 2014; Wu et al. 2016). In addition to aerosol backscattering (and thus LSR), the CRL provides profiles of water vapor and temperature. Water vapor mixing ratio (WVMR) is also conserved in the absence of condensation, and thus, CRL water vapor transects also can be used to reveal layer lifting. The CRL temperature measurements are not reliable in the immediate vicinity of cloud edges $(<0.1 \mathrm{~km})$ or within cloud, and none are used in this case study.

\section{c. Additional PECAN data sources}

In addition to UWKA observations, many of the PECAN mobile and fixed surface platforms sampled the 15 July MCS and, in particular, its leading convergent boundary zone, where new cells formed. This includes the fixed PISA (FP) stations FP2, FP3, and FP5, which operated Doppler lidars, Atmospheric Emitted Radiance Interferometers (AERIs), microwave radiometers, wind profilers, radiosondes, and instrument suites for common meteorological variables (Table 1). These instruments are necessary for surface measurements and profiles of wind and thermodynamic properties. Similar instruments (although usually not all of them) operated aboard many of the mobile PISAs (MPs).

Of particular interest are the AERIs, which measure downwelling thermal infrared spectra (Knuteson et al. 2004), from which profiles of temperature and water vapor are retrieved (Turner and Löhnert 2014; Turner and Blumberg 2018, manuscript submitted to IEEE Selected Topics Appl. Earth Obs. Remote Sens.). Although these retrievals have poorer vertical resolution than a radiosonde, and the information content is limited to the lowest $\sim 3 \mathrm{~km}$ AGL, their 2-min time resolution provides a detailed description of the profile change in time. Furthermore, Blumberg et al. (2017) have shown that convective indices, such as CAPE and CIN, computed from AERI retrievals compare favorably with those from collocated radiosondes, especially for $100-\mathrm{mb}$ $(1 \mathrm{mb}=1 \mathrm{hPa})$ mixed layer and surface-based calculations. We also compute local thermodynamic variables such as virtual potential temperature $\left(\theta_{v}\right)$, where pressure data are derived from the surface pressure and temperature profile, assuming hydrostatic balance.

Several mobile and fixed radars recorded MCS movement and intensity, as well as outflow fine lines. Radar reflectivity animations are used to determine the boundary's speed and orientation. The composite reflectivity mosaic shown in this study is combined from base $\left(0.5^{\circ}\right.$ elevation) reflectivity scans from all National Weather Service NEXRAD radars, plus the NCAR S-band dualpolarization radar (S-Pol). This product, produced by UCAR/NCAR-Earth Observing Laboratory (2016c), includes very weak echoes such as clear-air echoes along convergent boundaries, allowing a focus on radar fine lines. Finally, the MP2, MP3, and NSSL1 mesonet vehicles all intercepted the MCS (Table 1).

\section{15 July 2015 MCS synopsis}

This case study examines a large, long-lived but nonsevere MCS in western Kansas observed during the night of 14-15 July (15 July in UTC). The MCS originated in eastern Colorado, where widespread cellular convection merged around sunset (0200 UTC) and began moving eastward. ${ }^{1}$ Multiple outflow boundaries

\footnotetext{
${ }^{1}$ See radar reflectivity animation at http://flights.uwyo.edu/ projects/pecan15/nexrad/PECAN_July15_radar.html.
} 


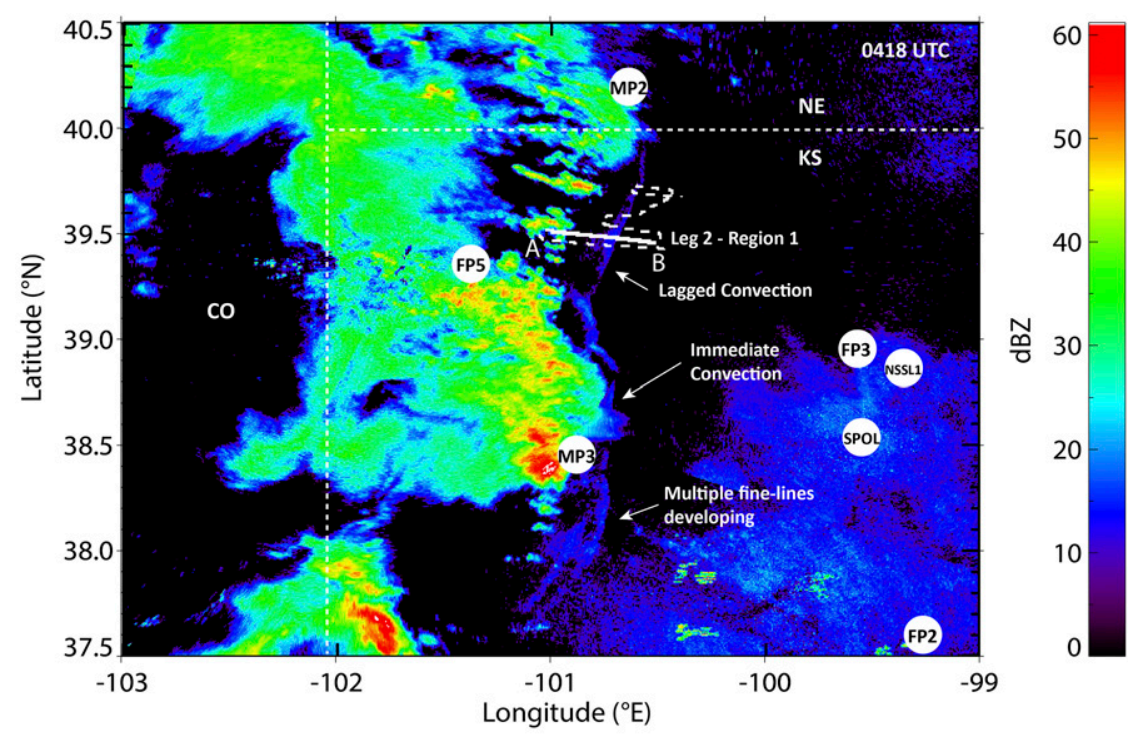

FIG. 2. Composite radar reflectivity at 0418 UTC 15 Jul 2015 showing locations of FPs (FP2, FP3, FP5), MPs (MP2, MP3, NSSL1), the S-Pol radar, and the first region of UWKA boundary transects. There are some strong ground clutter echoes due to wind farms in the southeastern corner of the figure.

became visible as radar fine lines around 0300 UTC. New cells formed along the leading line, especially on the southern side. By 0400 UTC, an MCS had formed, covering all of far-western Kansas and propagating eastnortheastward [Fig. 2; see also Fig. 2 in Geerts et al. (2017) for the PECAN domain]. A 500-mb ridge was present over the Great Plains, with weak $\left(7-10 \mathrm{~m} \mathrm{~s}^{-1}\right)$ southwesterly flow over western Kansas (not shown).

A southerly LLJ was present in many of the PECAN soundings with speeds as high as $22 \mathrm{~m} \mathrm{~s}^{-1}$ by 0600 UTC. During the eastward propagation of the MCS, some regions along the leading radar fine line experienced immediate CI where the leading precipitation echoes and the fine line were nearly indistinguishable. We refer to this, and any convection within $20 \mathrm{~km}$ of a fine line, as immediate convection (IC). Unfortunately, the UWKA did not fly across IC boundaries because it is not a storm-penetrating aircraft, and by design, on inbound legs, it made a $180^{\circ}$ turn away from strong radar echoes at $10 \mathrm{n} \mathrm{mi}(18.5 \mathrm{~km})$ range. In other regions, the convergent boundary (radar fine line) moved out ahead of the precipitation. Here, CI was not immediate, and the lag resulted in a gap in which the UWKA could penetrate and the AERIs on the ground could operate because the AERI's hatch was not closed until the immediate advent of rain. We refer to this as lagged convection (LC).

Following common practice (e.g., Locatelli et al. 1998; Wilson and Roberts 2006; Haghi et al. 2017), we use the presence of multiple parallel radar fine lines as a first indicator that the outflow boundary may be an undular bore, as opposed to a density current, which usually appears as a single fine line. The nature of the convergent outflow boundary remains unknown in IC areas where precipitation masked the fine line, although this rarely occurred. In most areas with IC, a fine line was evident directly ahead of the precipitation curtain, or the precipitation echoes were cellular with the fine line evident in the gaps between the cells, so the distinction between single and multiple fine lines can still be made. Where the outflow boundary was not visible (e.g., at MP3), local AERI and other observations were used to make the distinction.

When the MCS first formed and the outflow boundary became visible on radar (around 0200 UTC), IC dominated along the boundary. Where it could be discerned, the boundary appeared solely as a single line (density current) until $\sim 0400$ UTC ( $2 \mathrm{~h}$ after sunset) during the MCS's growth phase (Figs. 3a,c). In general, a single fine line (density current) preceded occurrences of IC (Fig. 3d). After 0400 UTC, the fraction of the outflow boundary with LC steadily increased (Fig. 3b) as the MCS transitioned from a period of strengthening to quasi steady and then decaying (Parker 2008). In cases of LC, both single- and multiple-line outflow boundaries were present, (Fig. 2) and between 0700 and 0800 UTC, the extent of LC stretched across as much as two-thirds of the radar-detected convergent boundary. During this same period, the extent of the outflow preceded by multiple radar fine lines reached a maximum (Fig. 3c), 

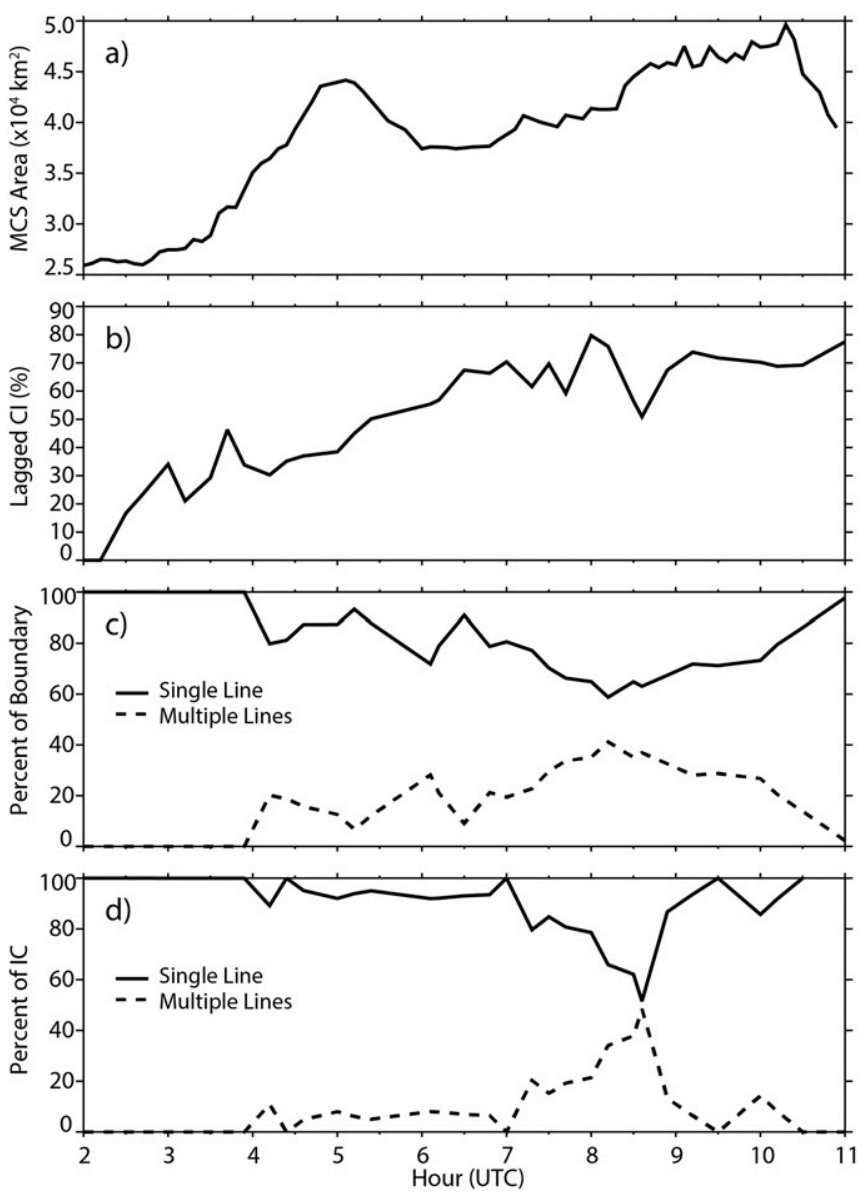

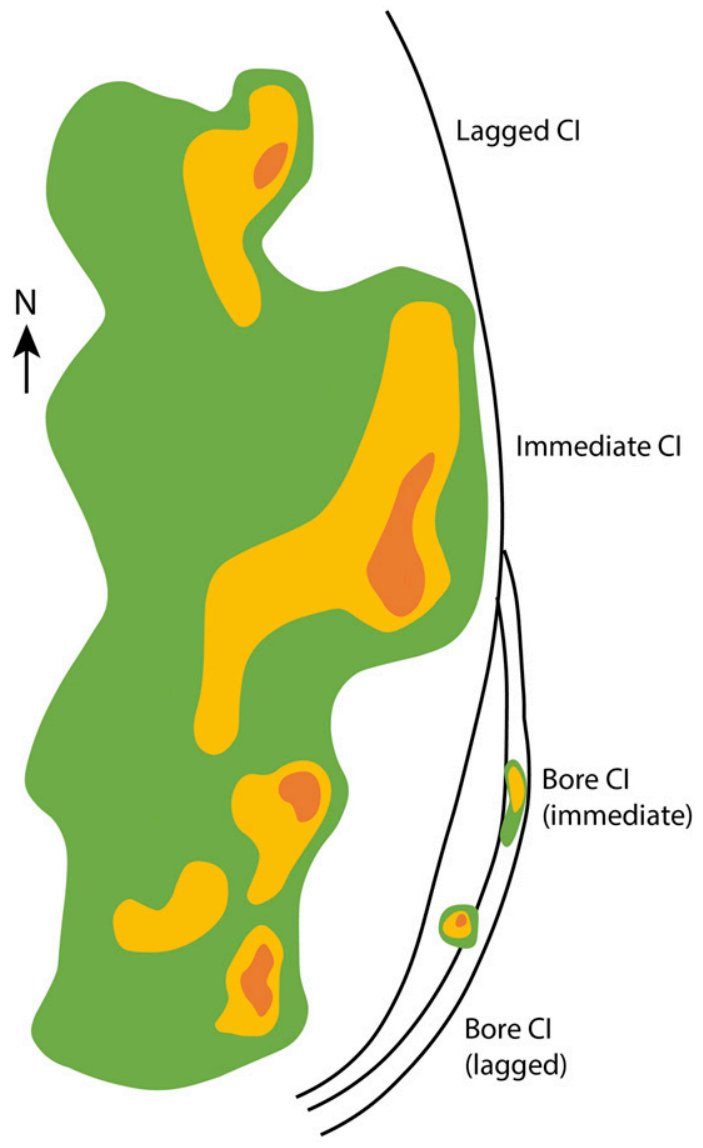

FIG. 3. (a) Area of the MCS (defined as reflectivity $>27 \mathrm{dBZ}$ ); (b) percent of the outflow boundary with LC; (c) percent of the outflow boundary comprising a single fine line vs multiple fine lines, where it can be discerned from the radar reflectivity composite and PISA data; and (d) percent of the IC behind a single fine line (DC) and multiple fine lines (bore or soliton). The radar illustration shows examples of lagged and immediate CI produced by DCs and bores.

while the percent of IC by single radar fine lines reached a minimum (Fig. 3d).

Some bores (with multiple lines) even produced IC, especially between 0700 and 0900 UTC. An increasing fraction of the outflow boundary became bore-like after 0400 UTC up until 0800 UTC (Fig. 3c) as the MCS matured, the nocturnal SBL deepened, and the LLJ intensified, producing a suitable environment for wave trapping, especially where the outflow boundary was oriented to the southeast, as will be shown below. The area the MCS covered increased during periods where the percent of multiple fine lines increased (0400-0500 and 0700-0900 UTC; Figs. 3a,c). This suggests that MCS size and longevity was enhanced by the formation of bore-like outflow boundaries, which produced sufficient vertical lift to allow new cell formation and discrete forward propagation. In turn, the larger MCS produced stronger outflows that enabled bore development.

\section{Convergent boundary classification and ensuing vertical displacement}

\section{a. Lagged and immediate convection initiation}

The 15 July PECAN intensive observation period (IOP) provided a spatially dense set of radiosondes that were often launched just before and just after the passage of a radar fine line. Such sounding pairs provide useful information about the nature of the convergent boundary and about the effective source level for new convective cells. Radiosonde observations ahead of IC initiation reveal a layer of potential instability that was released upon lifting over the outflow boundary (Fig. 4). Significant potential instability is found near $700 \mathrm{mb}$ in the MP2 and MP3 profiles, both adjacent to an IC outflow boundary (Fig. 2). Less potential instability was present near $700 \mathrm{mb}$ ahead of the outflow boundary at FP5 (Fig. 4a), located in an LC region between the two mobile PISAs (Fig. 2). Yet, most unstable CAPE (MUCAPE) is not suppressed at 

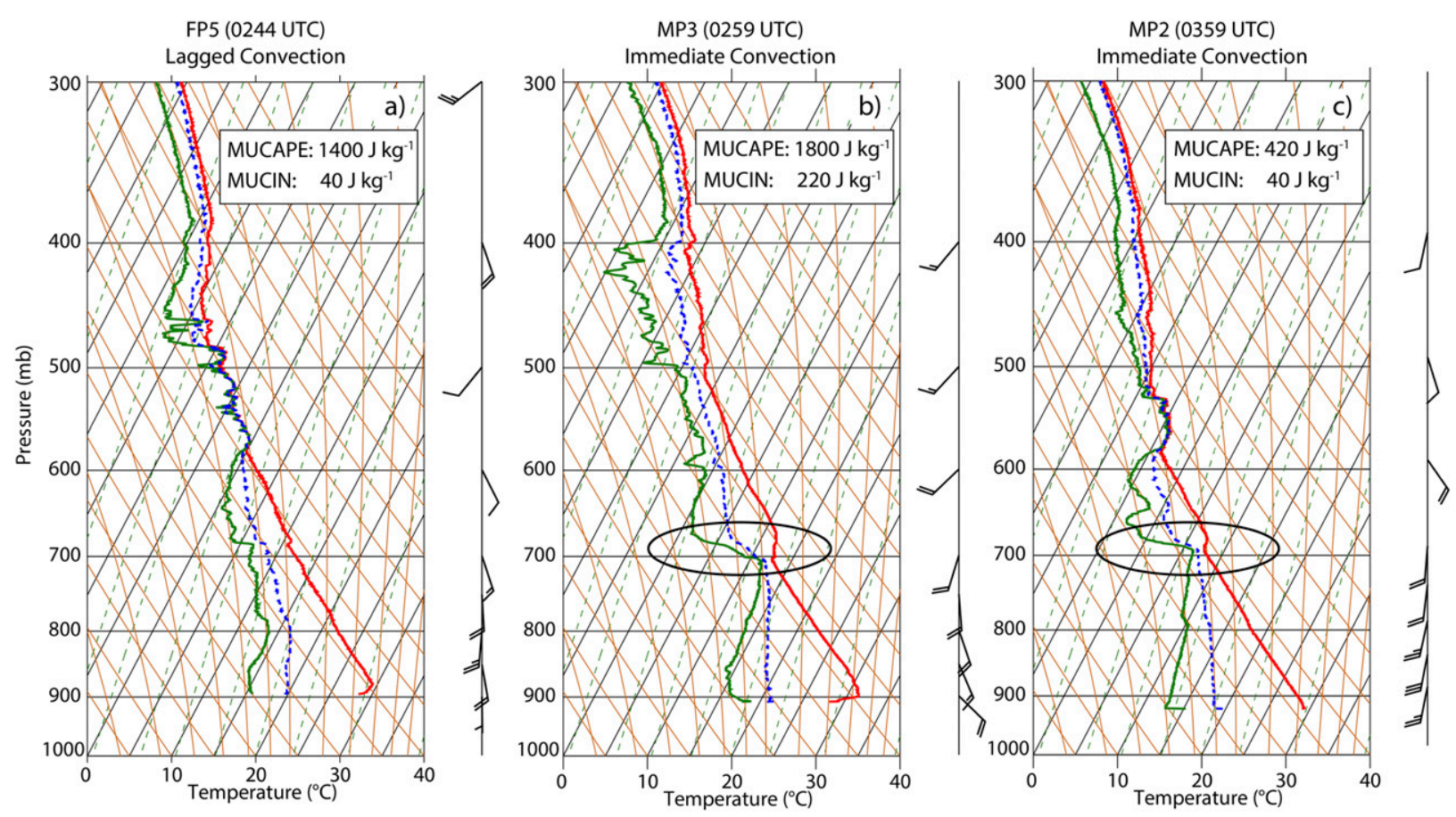

FIG. 4. Three soundings just ahead of the MCS outflow boundary, with LC at (a) FP5 and IC at (b) MP3 and (c) MP2. Refer to Fig. 2 for radar and sounding locations. Ellipses indicate locations of potential instability observed where the wet-bulb temperature (blue line) crosses moist adiabats with increasing height.

FP5, nor is the CIN at the level of MUCAPE higher at FP5 than at the adjacent locations with IC (MP2 and MP3). Rather, it appears that delayed convection at FP5 resulted from lessened lift: the most unstable air is lifted deeper over the density current at MP3 than at FP5, according to the AERI-derived $\theta_{v}$ profile data at these two locations (Fig. 5). The AERI at FP5 (Fig. 5a) suggests that the cold pool remained very shallow $(<500 \mathrm{~m}$ thick according to the $312-\mathrm{K}$ contour). In the hour following boundary passage, the cold pool depth increased. This delay nearly corresponds to the time it took the lagged convection to appear. Although the top of the density current at MP3 is less defined, the $\theta_{v}$ contours have larger slopes (Fig. 5b). The 312-K contour quickly surpasses $500 \mathrm{~m}$, reaching $1 \mathrm{~km}$ by the time the AERI hatch was closed due to rain.

Being early in the night, both FP5 and MP3 sites had a very shallow SBL (Table 2). A few hours later, at FP3 farther east (Fig. 2), the SBL was deeper $(\sim 620 \mathrm{~m})$. The density current was also much deeper at FP3 than at FP5/MP3, with steep $\theta_{v}$ contours (Fig. 5c), and its arrival only marginally preceded the onset of convective rain. Assuming $\theta_{v}$ is conserved, parcels near the top of the SBL were lifted as much as $2 \mathrm{~km}$.

\section{b. UWKA density current and bore transects}

The separation that occurred between the MCS precipitation and outflow boundary in LC regions allowed the boundary to be studied with the profiling lidars aboard the UWKA. These observations are used in an effort to understand the lifting mechanism and effective source level for CI in LC regions. Specifically, we use the airborne lidar data to determine the actual vertical displacement for parcels at all possible source levels and compare this against the vertical distance to the parcel's LFC.

The UWKA completed a total of 20 transects across three convergent boundary zones leading this MCS. The first zone, referred to as Region I (Fig. 2), is located near FP5 and was sampled between 0340 and 0410 UTC, when the SBL was still relatively shallow (Table 2). The outflow boundary in Region I displays the characteristics of a classic density current (Fig. 6). In the WCL LSR transect, the cold pool appears rather shallow $(\sim 600 \mathrm{~m})$, which is consistent with the FP5 sounding released a few minutes after the transect in Fig. 6 (Table 2) and the AERI observations in Fig. 5.

The next two zones (Regions II and III) were farther south. Radar imagery of both southern zones displayed multiple, parallel fine lines moving away from the MCS (Fig. 7). The bore-like (multiple line) appearance occurs where the boundary is oriented southwest (SW)-northeast (NE), where much boundary-normal low-level wind shear exists on account of the LLJ (Fig. 8). This LLJ, directed from the southeast (SE), is very shallow $(\sim 300 \mathrm{~m})$ yet 

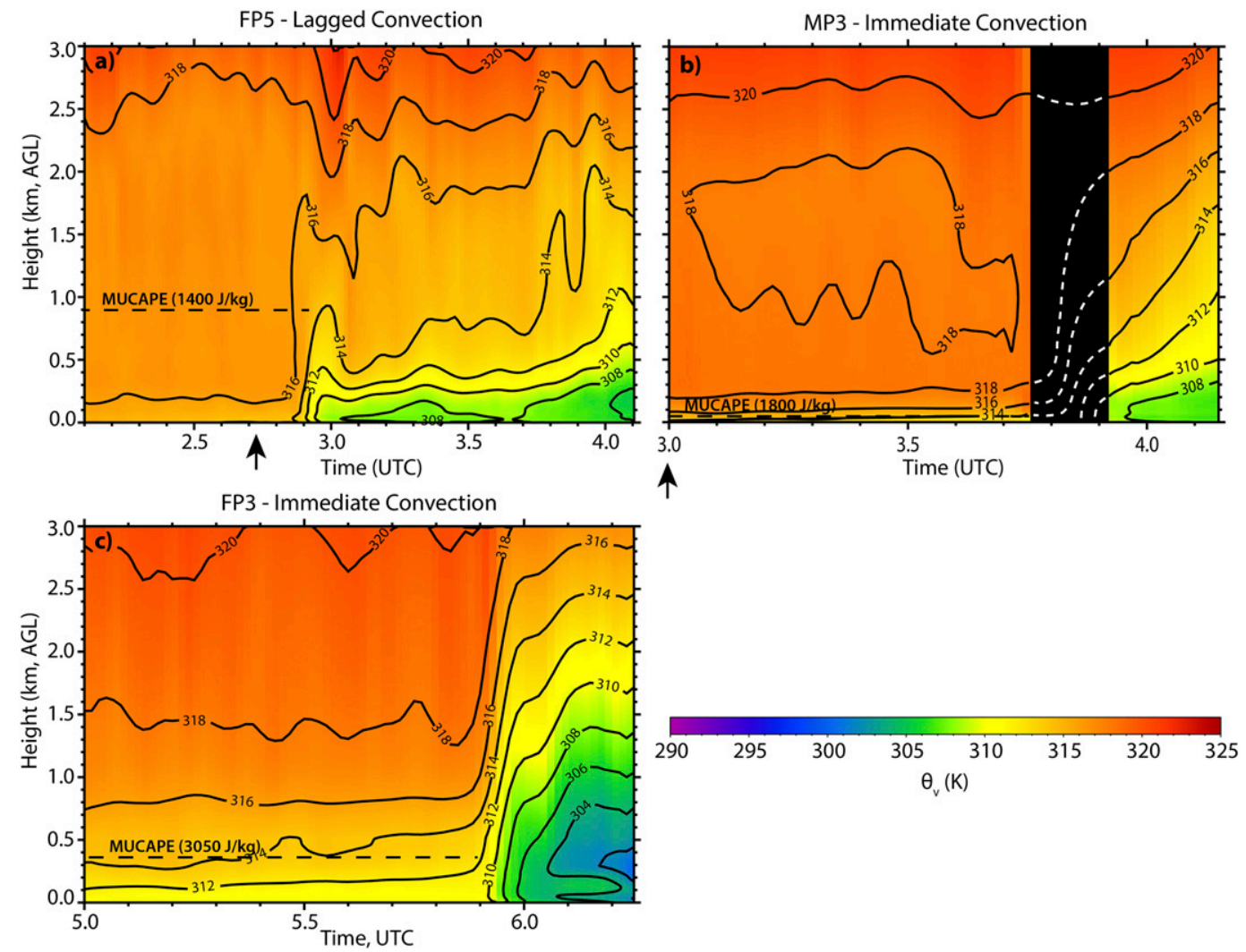

FIG. 5. AERI-derived virtual potential temperature during the passage of DCs at (a) FP5, (b) MP3, and (c) FP3. Horizontal dashed lines indicate the location and amount of MUCAPE $\left(\mathrm{J} \mathrm{kg}^{-1}\right)$. Where a period of bad data is blacked out at MP3, $\theta_{v}$ contours (white dashed lines) were manually drawn. Arrows indicate time of radiosonde launch for MUCAPE calculation; FP3 radiosonde was launched at 0400 UTC.

strong $\left(\sim 18 \mathrm{~m} \mathrm{~s}^{-1}\right)$. A single line (density current) was present where the boundary was oriented meridionally [south (S)-north (N)] or even SSE-NNW. Because of the boundary-normal wind curvature across the LLJ near the top of the SBL, the Scorer parameter $\ell^{2}$ becomes negative around $0.4 \mathrm{~km}$ AGL in the FP2 sounding (Fig. 9), located on the south side of the MCS (Fig. 7). The Scorer parameter is defined as

$$
\ell^{2}=\frac{N^{2}}{(U-C)^{2}}-\frac{\frac{\partial^{2} U}{\partial z^{2}}}{(U-C)},
$$

where $N$ is the Brunt-Väisälä frequency, $U$ is the environmental wind normal to the direction of boundary movement, $C$ is the speed of the boundary, and $z$ is the vertical distance. Radiosonde data used for the calculation were smoothed by a 60 -m-deep moving average and then interpolated to a 50-m-resolution normal grid using the spline method. The condition $\ell^{2}<0$ is favorable for wave trapping and bore maintenance (Crook 1988), hence the prevalence of multiple fine lines on the south side of the MCS. The Scorer parameter for the five other sounding locations, all located farther north along the MCS (not shown), did not have extensive negative regions in the lowest $3 \mathrm{~km}$ AGL.

The UWKA completed four short transects in Region II before convection closed in. This CI was in response to deeper lifting along the intersection between a northeastward-moving density current and the southeastward-propagating bore (Fig. 7). Last, the UWKA completed 10 transects in Region III (Fig. 7). These 10 transects were long enough to sample both radar fine lines, revealing wavelike water vapor and LSR structures in the lidar transects (Figs. 10a,b). The radar fine lines are evident in the radar reflectivity trace along flight level in Fig. 10c.

The LSR (Fig. 10a) and water vapor mixing ratio (Fig. 10b) transects from one of the legs in Region III (leg 8; see Fig. 7) clearly show two wave crests within and above the SBL, with a wavelength of about $11 \mathrm{~km}$. The waves are vertically stacked (do not tilt with height), and their amplitude appears to decrease with height (i.e., they are likely evanescent) with wave energy trapped. 


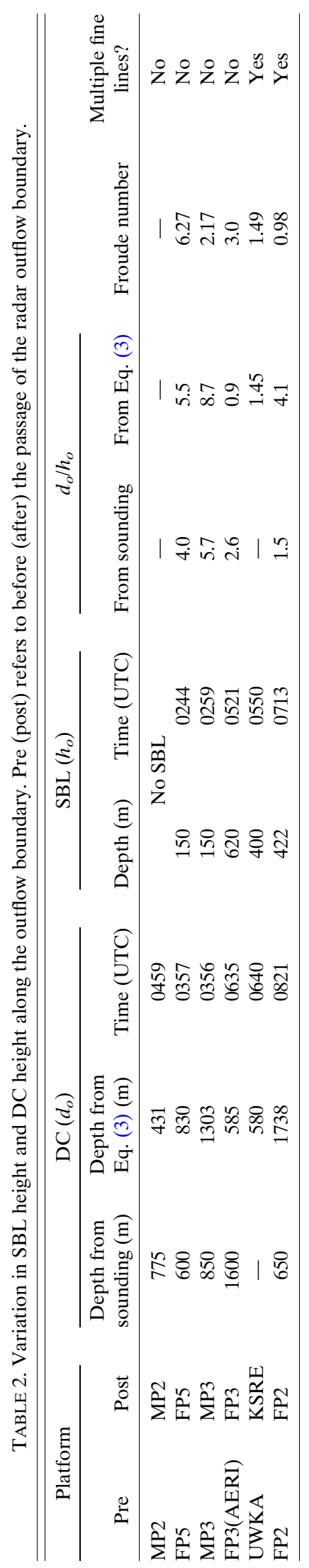

The moist SBL (with high values of water vapor mixing ratio; Fig. 10b) is lifted by the first undular wave, descends again, and is lifted higher in the second wave. This second wave disperses the water vapor, implying that the wave breaks down into turbulence, indicative of a bore of high strength $(S)$, defined as the ratio of bore depth over SBL depth (Rottman and Simpson 1989). The actual bore strength is $2<S<3$. Bores with $2<S<4$ typically display mixing and turbulence on the downstream side (Rottman and Simpson 1989), but this turbulence does not reach flight level $(600 \mathrm{~m}$ above the second wave crest); the UWKA experienced only light turbulence [eddy dissipation rate $($ EDR $)<0.05 \mathrm{~m}^{2 / 3} \mathrm{~s}^{-1}$; Fig. 10d]. Liquid drops within clouds just above flight level extinguish the zenith lidar beam for both waves $(0<x<22 \mathrm{~km})$. The second wave had a higher amplitude than the first one, consistent with the long-lived bore described in Mueller et al. (2017). The resulting lift was sufficient to create a cloud in the second wave crest, peaking at $1.2 \mathrm{~km}$ AGL. The lidar transect does not reveal a cumuliform cloud top, implying that the lower cloud layer was not lifted above the LFC. Two loweramplitude waves are visible in the water vapor and LSR trace at low levels near $x=30$ and $35 \mathrm{~km}$ (Figs. 10b,c), but these perturbations are not felt at flight level.

The bore-normal wind speed increased as flow moved over the bore-solitary wave system from right to left (Fig. 10d). Local minima and maxima existed above the troughs and crests, respectively. Increases in speed can be explained by considering the continuity equation. As the wave amplitude and vertical displacement appear to decrease with height (Figs. 10a,b), flow above the SBL is forced through a smaller depth above ridges as the SBL depth is raised by the bore. Areas of upward motion at flight level (Fig. 10e) agree well with where flight-level along-track divergence occurs ahead of each wave, and areas of downward motion occur behind each crest where the along-track flow is convergent. This confirms the decrease in vertical displacement with height. Potential temperature (Fig. 10f) shows relatively little change as the flight level is within the rather well-mixed residual layer, decreasing only slightly by net adiabatic ascent. Equivalent potential temperature $\left(\theta_{e}\right)$ (Fig. 10f) and in situ water vapor (Fig. 10c) indicate that a level containing more moisture exists near flight level, and drier air is lifted at wave crests.

Flight-level pressure perturbations relative to a reference geopotential height surface are accurately measured due to differential GPS aircraft altitude information. We define the reference geopotential height to be the average along the flight track, such that the pressure perturbations average out to zero (Fig. 10e). Positive pressure perturbations above troughs and negative perturbations above wave crests are not consistent with hydrostatic 


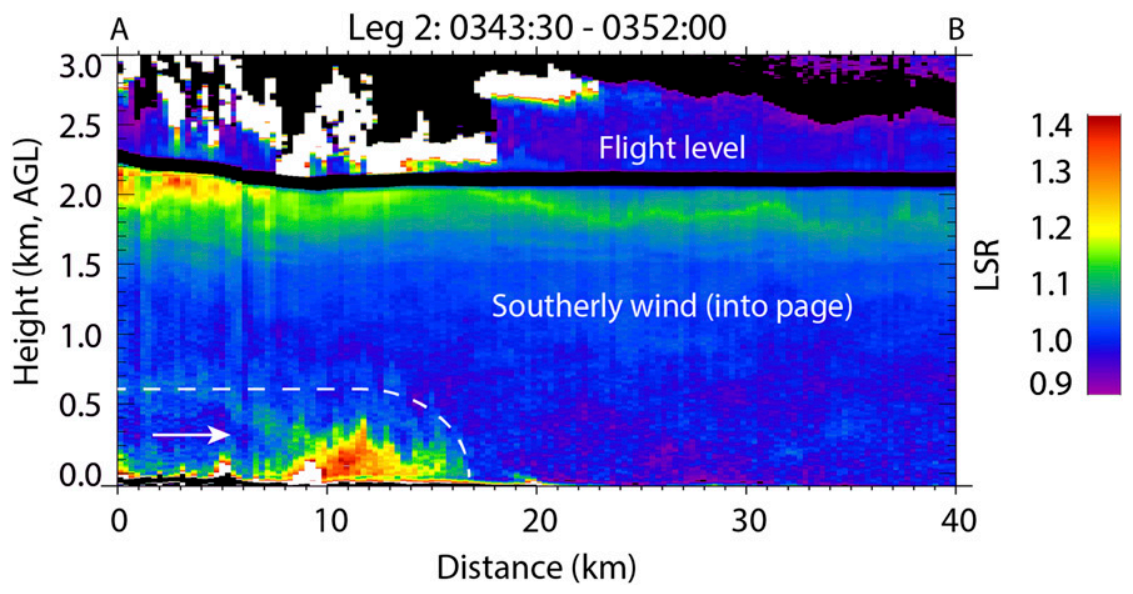

FIG. 6. UWKA LSR across the DC in Region I (see Fig. 2). The white line is the approximate boundary of the DC from the LSR values. The arrow indicates direction of motion.

theory, considering that temperature should be lowest above wave crests. Dynamic pressure perturbations dominate in this case, as evident by applying the Bernoulli principle to an air parcel moving from right to left. Ahead of the first wave to its crest, the parcel accelerates from 5.2 to $8.2 \mathrm{~m} \mathrm{~s}^{-1}$. Thus, according to the Bernoulli equation,

$$
p_{1}^{\prime}+\frac{1}{2} \rho v_{1}^{2}=p_{2}^{\prime}+\frac{1}{2} \rho v_{2}^{2}
$$

the corresponding nonhydrostatic pressure drop is $0.25 \mathrm{mb}$. This nearly matches the observed pressure drop of $0.31 \mathrm{mb}$. Here, pressure perturbation $p^{\prime}$, density $\rho$, and velocity $v$ are subscripted with 1 and 2 for values at the trough and crest, respectively. It must be assumed that air velocity measured at troughs or crests is representative of other layers of air slightly above or below flight level, which is acceptable, given that the flight level remains within the rather well-mixed residual layer. These pressure perturbations at $1.8 \mathrm{~km}$ AGL are small,

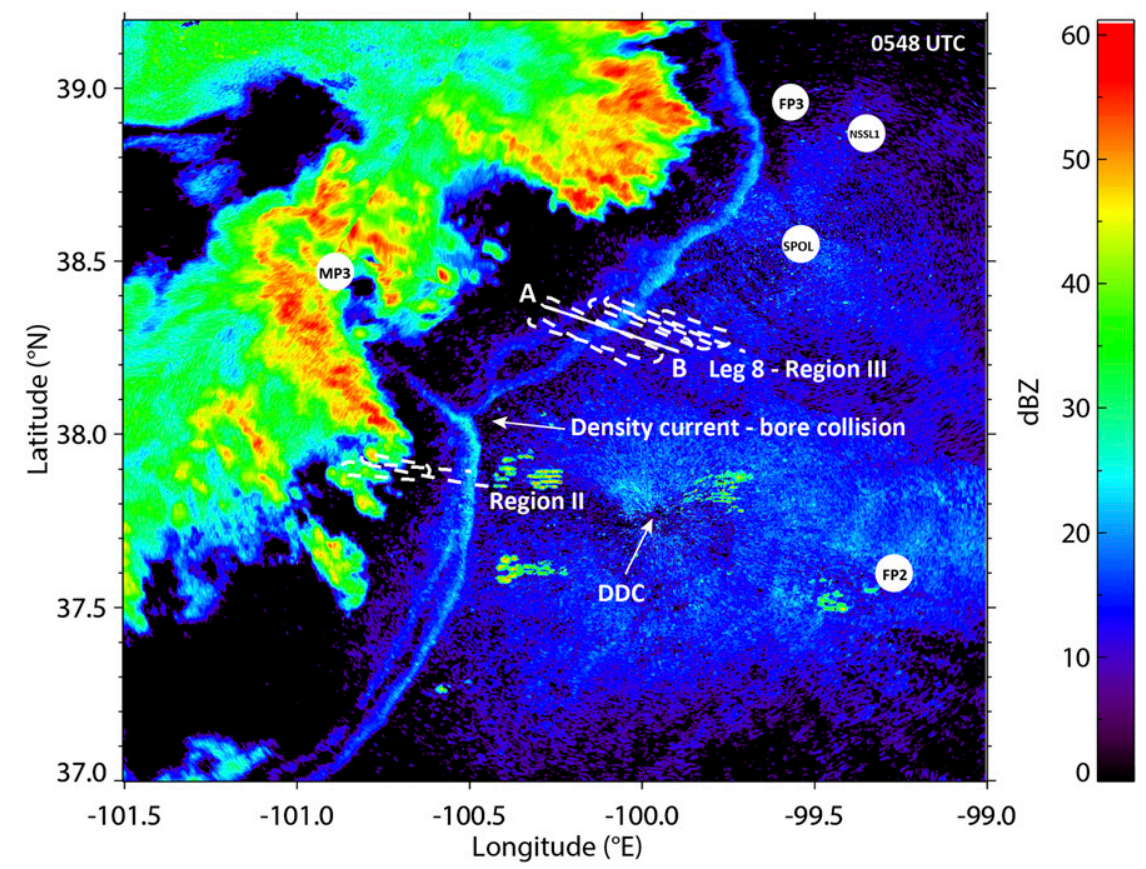

FIG. 7. Composite radar reflectivity in west-central Kansas [Dodge City (DDC)], revealing areas of multiple radar fine lines on the southeast side of the MCS. The UWKA flight leg 8 and other flight legs are shown as a white solid and dashed line, respectively. 


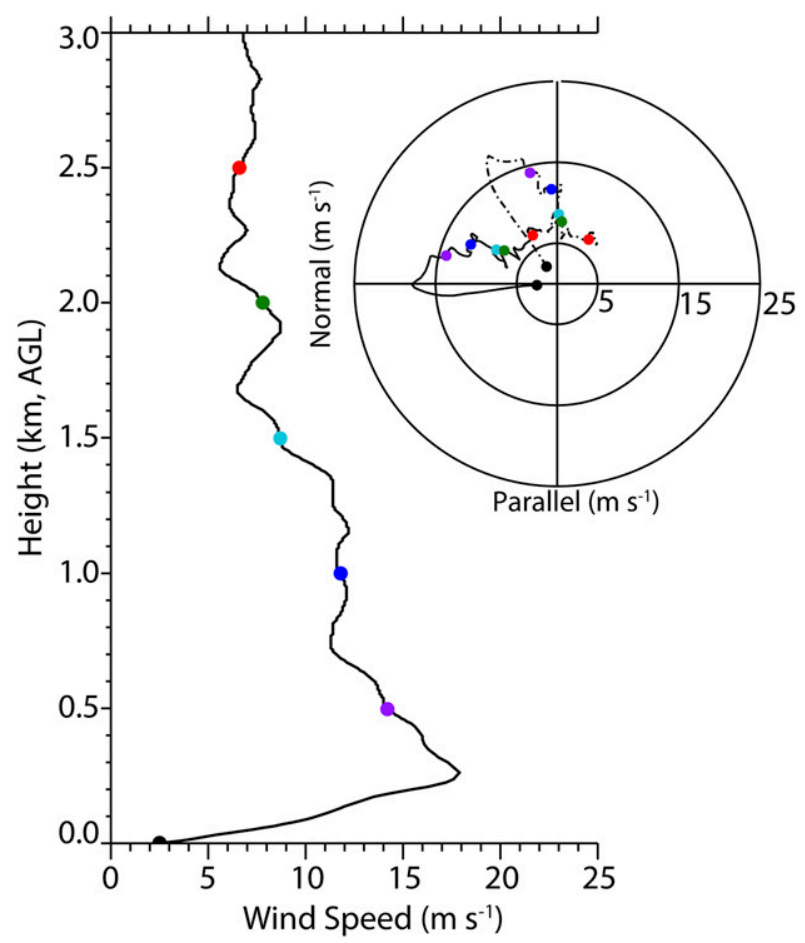

FIG. 8. Wind speed profile and hodograph from NSSL1 at 0603 UTC. The hodograph is rotated relative to the local orientation of the outflow boundary. The dashed line applies to a boundary oriented roughly meridionally (as observed north of NSSL1; Fig. 7) and the solid line to a boundary oriented roughly SW-NE (as observed south of NSSL1). The color dots identify different heights at 500-m intervals.

compared to those observed on the ground, as will be shown below.

\section{c. Bore-induced vertical displacements}

Lidar measurements of water vapor and LSR can provide estimates of layer displacement to give insight into how the bore and solitary wave modified the lowertropospheric stability. Because water vapor mixing ratio is conserved (in the absence of condensation), its isolines in a vertical transect represent parcel (or layer) vertical motions in a stratified environment (Koch et al. 1991; Mueller et al. 2017). The LSR can provide a comparable estimate of layer displacement, as different layers have different aerosol concentrations, although LSR values are not conserved through vertical motion because hygroscopic aerosols can accumulate liquid water and reflect the lidar beam differently.

The vertical displacement of CRL water vapor mixing ratio contours of 14,16 , and $18 \mathrm{~g} \mathrm{~kg}^{-1}$ and that of any visible aerosol layers was tracked for each of the 10 UWKA legs. The thermodynamic changes resulting from these displacements were then examined using a nearby sounding launched by NSSL1 (Fig. 11a). Temperature and moisture at each level of the sounding were used to calculate parcel-specific CAPE, CIN, LCL, and LFC (Figs. 11b,c). The black dots in Fig. 11c are the parcel displacements estimated from the UWKA. Generally, displacements tend to decrease with height, as would be expected from an evanescent wave. Clouds directly above flight level (dashed line) prevented the upward-pointing lidar signal from penetrating any higher than what is plotted. The displacement of parcels near the surface exceeded $1 \mathrm{~km}$ for each of the 10 flight legs. Even with such vertical motion, these layers were within the SBL, where parcels were far from their LFCs and unlikely to initiate convection. Layers aloft also experienced considerable displacements, as much as $800 \mathrm{~m}$ near flight level. It is these layers in the residual layer that have greater potential for becoming the source of elevated CI. Layers initially near $0.5 \mathrm{~km}$ and above $1.2 \mathrm{~km}$ (up to $\sim 2.0 \mathrm{~km}$ ) could be lifted above their LCL to form cloud, shown by the dots to the right of the LCL (Fig. 11c). This is corroborated by UWKA lidar observations that observed clouds on the crest of the bore at low levels and near flight level. The moisture in these layers contributes to the high CAPE, low CIN environments essential for effective inflow layers into an MCS. None of the observed layer displacements obviously surpassed their LFC. Local LFC heights are quite low for the layer originally at $2.5-3.0 \mathrm{~km}$ AGL. Although very high, this layer still has over $750 \mathrm{~J} \mathrm{~kg}^{-1} \mathrm{CAPE}$ and nearly no CIN and thus is a prime region for elevated CI. It is unfortunate that clouds blocked this region from view of the lidar.

\section{d. Bore propagation speed and flow regime}

Ground-based radar and airborne lidar were both used for estimating the bore-solitary wave speed during the period of airborne observations. For both methods, the latitude and longitude of the first fine line (or first wave crest on lidar) were noted to determine distance and then speed. Because lidar points were not in the same line, they were projected onto a transect normal to the boundary before speed was calculated. The average ground-relative bore speed on radar was $6.1 \mathrm{~m} \mathrm{~s}^{-1}$, decreasing steadily from 8 to $4 \mathrm{~m} \mathrm{~s}^{-1}$ during the MCS lifespan. The UWKA lidar estimate is $7 \mathrm{~m} \mathrm{~s}^{-1}$, and the theoretical estimate from Eq. (3) (Klemp et al. 1997) is $10 \mathrm{~m} \mathrm{~s}^{-1}$; both estimates are based on data early in the MCS lifespan. In Eq. (3), reduced gravity $g^{\prime}$ is calculated as $g^{\prime}=g\left(\Delta \theta_{v} / \theta_{v}\right), S$ is the bore strength, and $h_{o}$ is the unperturbed SBL depth:

$$
C_{b}=\sqrt{g^{\prime} h_{o}} \frac{S}{\sqrt{(1+S) / 2}} .
$$

Other case studies have observed a deceleration of the convergent boundary (or radar fine line) associated 

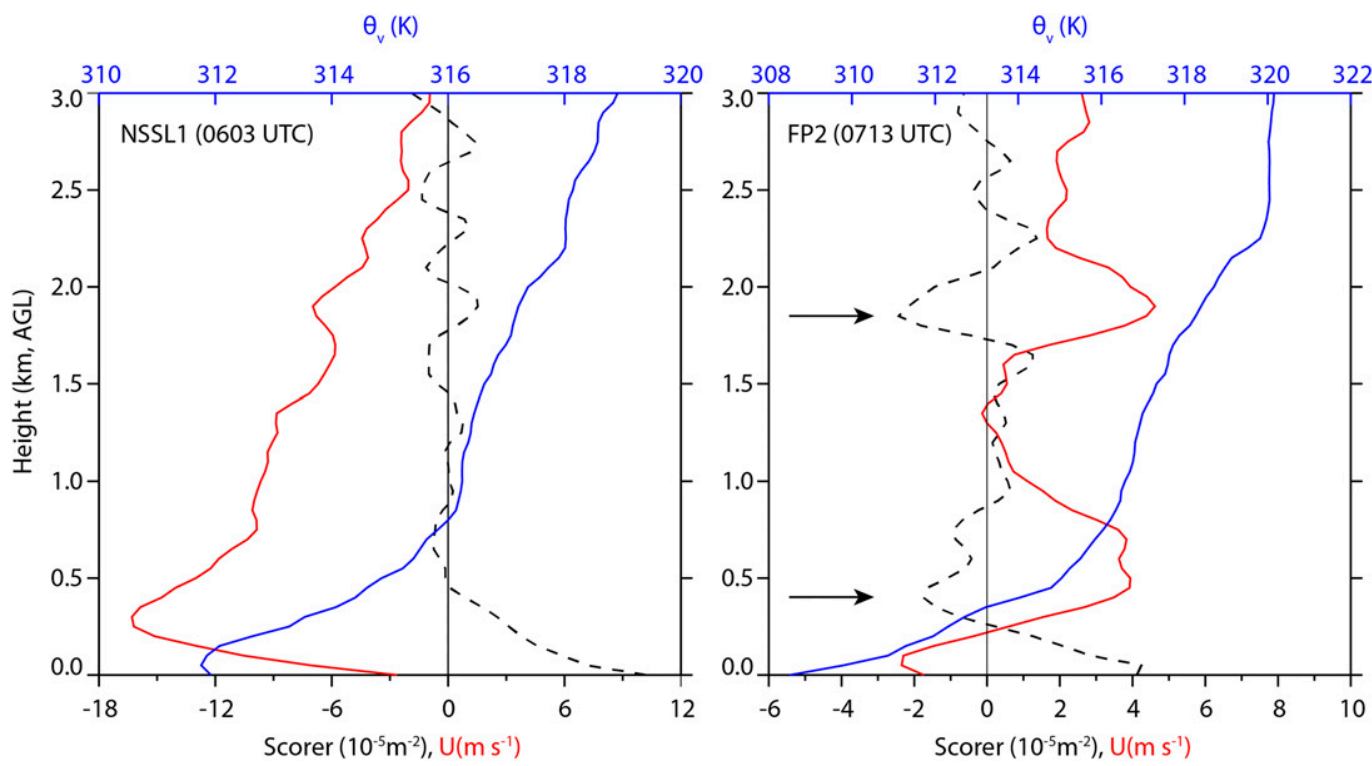

FIG. 9. Scorer parameter (dashed), boundary-normal wind speed (red), and virtual potential temperature (blue) for NSSL1 and FP2. NSSL1 is oriented for the waves observed by the UWKA in Fig. 10, and FP2 is oriented for the bore passage there. Arrows mark two trapping layers at FP2.

with a bore (Simpson 1987; Fulton et al. 1990; Koch et al. 1991). Koch and Clark (1999) attribute the deceleration to erosion of the gravity current by bore formation. Hartung et al. (2010) attributed the change in the bore propagation speed to the quality of the wave duct it was propagating in. In simulations of a density current with a low-level stable layer, Liu and Moncrieff (2000) found that the head of the density current was irregular in high stability. Propagation speed would oscillate as the density current head formed, accelerated ahead of the feeder flow, and then decayed repeatedly. In a manner possibly related to this process, observations from the S-Pol radar show both fine lines becoming less coherent between 0618 and 0624 UTC before decaying, shortly after the UWKA's last leg. A single fine line then regains coherency by 0636 UTC, as it accelerates with characteristics of a density current.

\section{Modification of the thermodynamic profile: Density current versus bore}

\section{a. Sounding analysis}

During the IOP, many of the PISAs launched radiosondes ahead of the outflow boundary and after its passage. These provide a unique insight into the effect of the boundary on the nocturnal environment, as well as the variability of the environment that influenced the boundary type. In this section, the soundings are used to show changes in CAPE, CIN, LFC height, and wind shear. The LC density current passage at FP5 at 0254 UTC resulted in decreases of CAPE and $\theta_{e}$ below about $1.25 \mathrm{~km}$ AGL (Fig. 12). The intrusion of the cooler air at the surface increased CIN as well as LFC heights. While the likelihood for surface-based thunderstorms further diminishes, changes tend to favor elevated CI. Increases in $\theta_{e}$ above $1.25 \mathrm{~km}$ AGL (Fig. 12d) suggest layer ascent over the density current. CAPE increases slightly near $2.0 \mathrm{~km}$ AGL, and, more importantly, CIN nearly vanishes, with just a few hundred meters' distance to the layer-specific LFC. Thus, the possibility of elevated CI has increased.

At all PISA sites experiencing density current passage (MP2, MP3, FP5, and FP3), the wind shear normal to the boundary (i.e., horizontal vorticity along the boundary) over the depth of the density current changed sign upon passage, but the magnitude of the density currentgenerated shear (obtained from the postboundary sounding) was larger than the magnitude of the ambient shear (preboundary sounding) by as much as a factor of 10 , both in the IC cases (MP2, MP3, and FP3) and in the LC case (FP5). So, the ambient shear was in a suitable direction for new cell formation (Rotunno et al. 1988; Weisman and Rotunno 2004), although rather weak. In effect, new convection would tilt upshear and lag behind the outflow boundary, which was observed throughout the MCS's life.

About $5 \mathrm{~h}$ after the density current passage at FP5, a bore-like outflow boundary producing new cellular convection passed FP2 and is well removed from the MCS (Fig. 13b). Similar to the density current passage at FP5, 

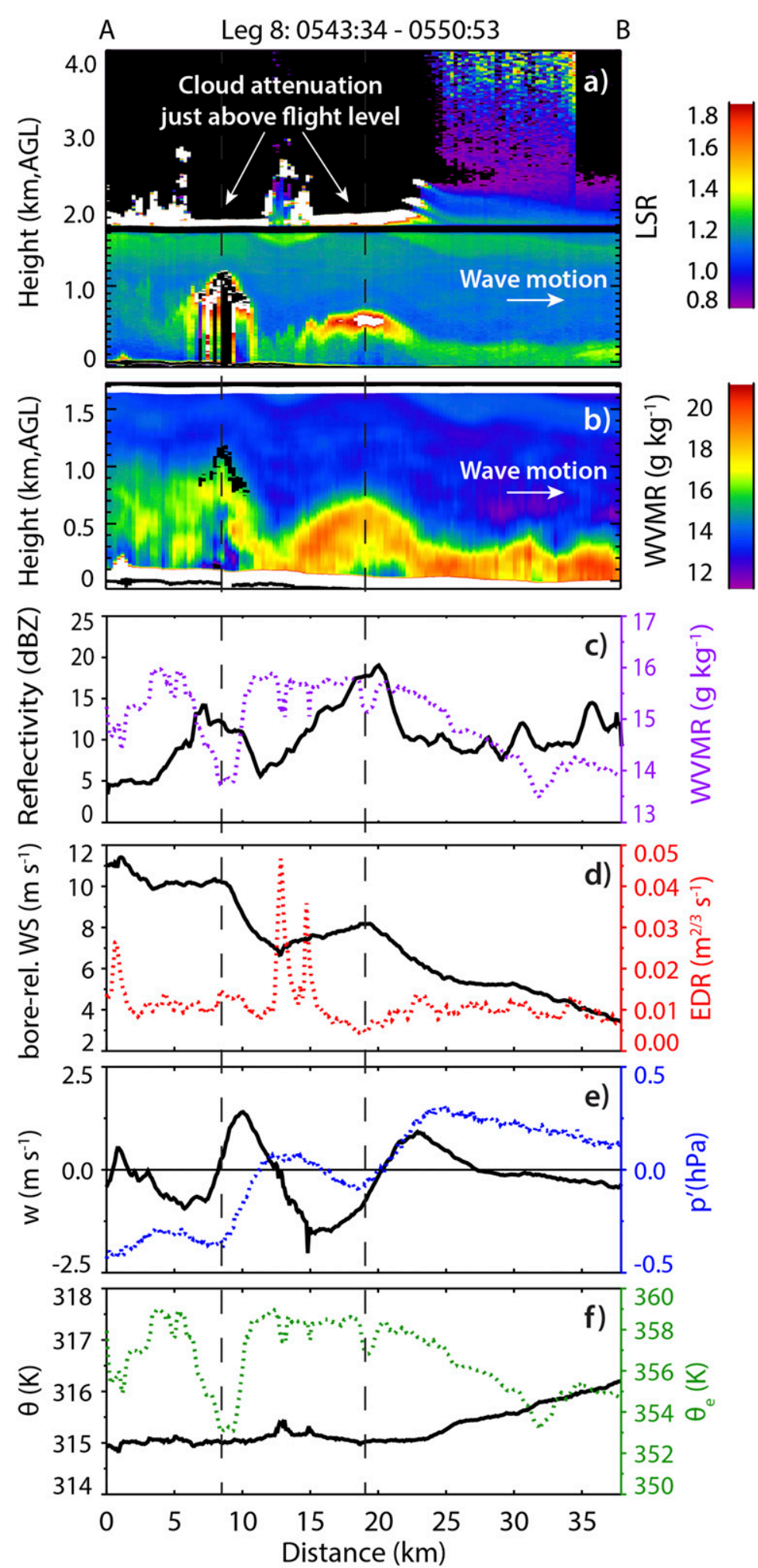

FIG. 10. UWKA leg 8 (Region III; Fig. 7) over two parallel radar fine lines. (a) Up/down LSR (the black line is the flight level); (b) CRL WVMR, down only; (c) radar reflectivity along flight track taken from the national radar mosaic at 0548 UTC and in situ WVMR; (d) wind speed normal to radar fine line and EDR; (e) vertical velocity and pressure perturbations; and (f) potential temperature and equivalent potential temperature. Black dashed lines mark wave crests. 

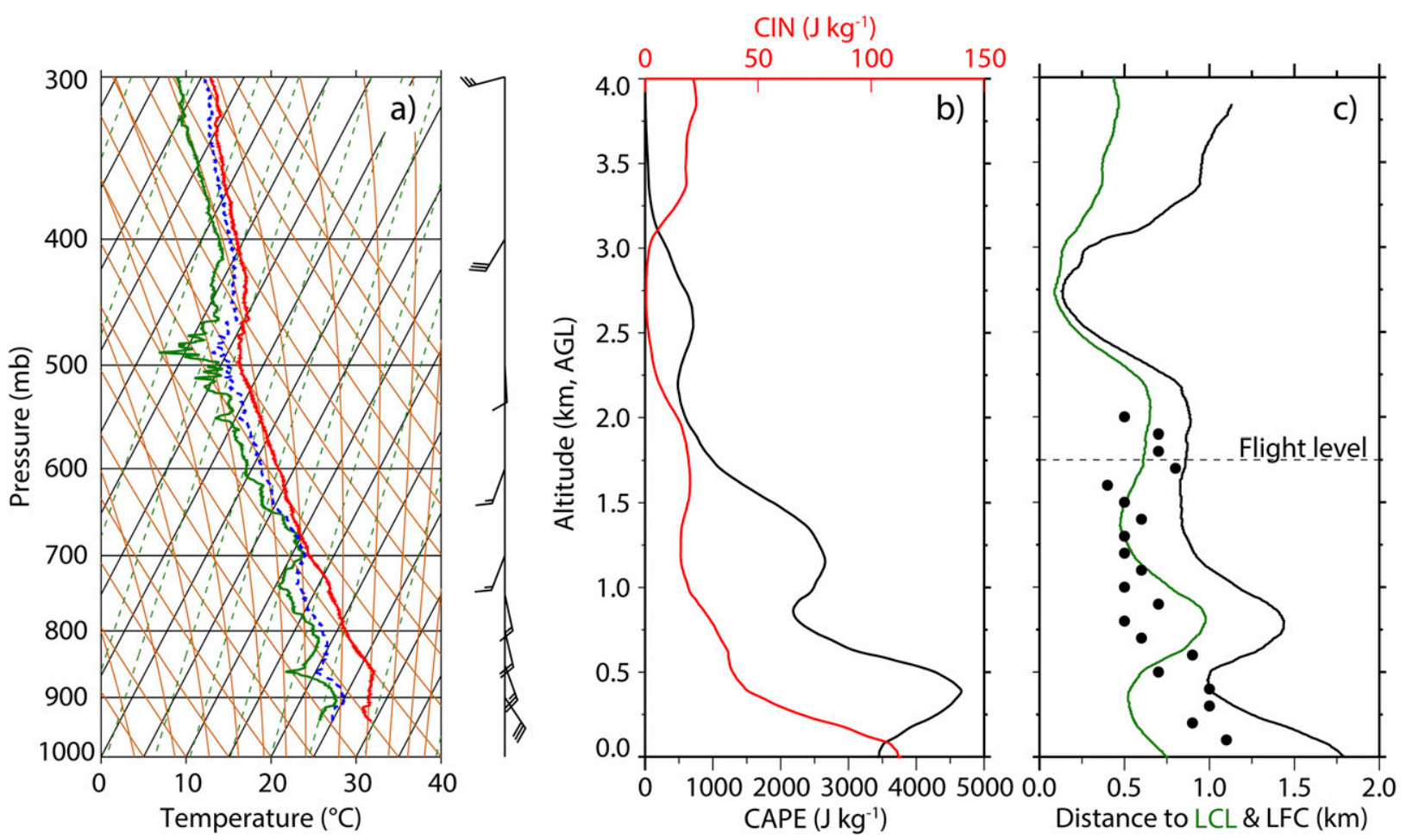

FIG. 11. (a) The sounding launched by NSSL1 (0603 UTC). (b) Parcel-specific CAPE and CIN and (c) parcel-specific LCL and LFC height (e.g., a parcel at $1.25 \mathrm{~km}$ with an LCL distance of $0.5 \mathrm{~km}$ would become saturated when lifted to $1.75 \mathrm{~km}$ ). Black dots indicate the largest actual vertical displacement observed at each level by the UWKA using WVMR and aerosol layers. (b),(c) The lowest $4 \mathrm{~km}$, where positive CAPE exists.

low levels experienced a general decrease in CAPE and an increase in CIN, although the changes are much smaller because environmental low-level CAPE (CIN) had been decreased (increased) by nighttime cooling. In the region near $2.5 \mathrm{~km}$ AGL, however, lifting caused CAPE and $\theta_{e}$ to increase, while CIN and distance to LFC become very small, similar to FP5. Here, the CAPE and $\theta_{e}$ changes are larger, as much as $1000 \mathrm{~J} \mathrm{~kg}^{-1}$ for CAPE. However, we cannot attribute these changes purely to the bore, as surface cooling suggests that a density current arrived before the radiosonde was launched. To separate the effects of the density current and bore passage between radiosonde launches, continuous measurements are needed. These are provided by the AERIs at these same locations, as discussed next.

\section{b. AERI}

The FP5 and FP2 sites both operated AERIs. Vertically integrated variables like CAPE and CIN are computed from AERI-retrieved profiles of temperature and water vapor as follows: temperature and dewpoint profiles above $3 \mathrm{~km}$ AGL from locally released radiosondes are spliced onto the AERI profiles. In each 2-h series of AERI data shown in Figs. 14 and 15, there are two radiosondes breaking up the time series into three sections: we use the first radiosonde for the first section (before its release) and the second radiosonde for the last section, and for times in between, we linearly interpolate between the two radiosondes. These two figures also show the radiosonde temperature and dewpoint profiles below $3.0 \mathrm{~km}$ AGL to compare with the AERI retrievals. The temperature profiles compare rather well, but the AERI water vapor values are lower than the radiosonde values (Figs. 14 and 15). This is not surprising: compared to water vapor, temperature has both a higher information content in the AERI radiance data and is better constrained by the a priori data, thereby leading to a better solution in the thermodynamic profile retrieval, which inherently is an ill-posed problem (Blumberg et al. 2017). The radiosonde and AERI retrievals do show the same trend with water vapor aloft increasing after boundary passage.

The density current arrived at FP5 at 0254 UTC (Fig. 14a), after which the surface temperature dropped considerably. The $312-\mathrm{K} \theta_{v}$ contour, a good indicator of density current depth in this case, reveals an elevated head leading the density current. As moisture was lofted, the water vapor mixing ratio increased 

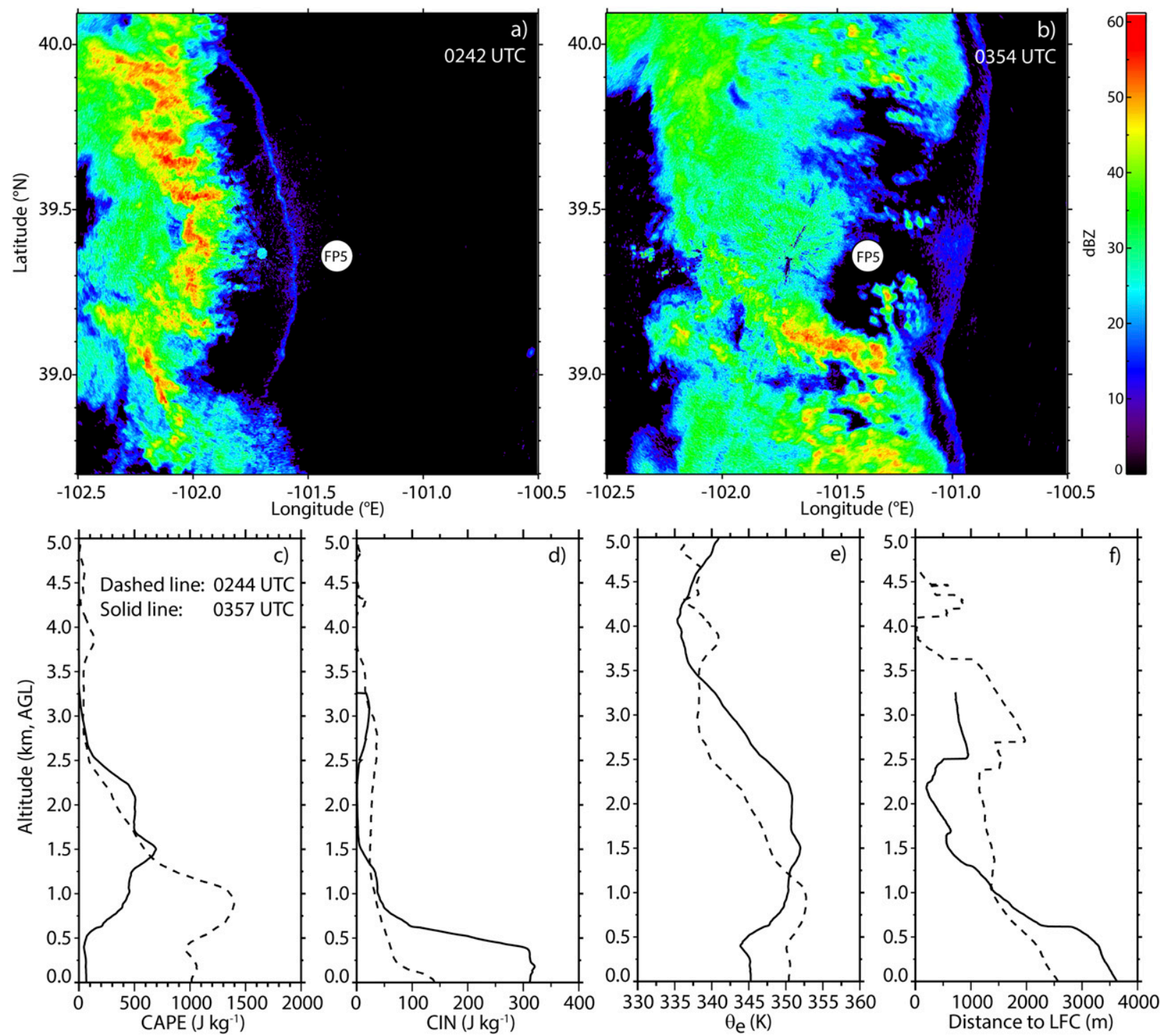

FIG. 12. Sounding location (a) before and (b) after the DC passage at FP5. (c)-(f) Changes in layer-specific CAPE, CIN, $\theta_{e}$, and LFC height between radiosonde launch times at 0244 (dashed) and 0357 UTC (solid).

by at least $4 \mathrm{~g} \mathrm{~kg}^{-1}$ around $1.5 \mathrm{~km} \mathrm{AGL} \mathrm{(Fig.} \mathrm{14b).}$ Undulations of unknown origin, with variable periods around $10 \mathrm{~min}$, can be seen in the water vapor field, mainly at $1.5 \mathrm{~km}$ AGL, before and after density current passage. We are confident that these undulations are real, based not just on AERI retrieval arguments, but also on dynamical ones, related to phase relationships and oscillation frequency. They probably are internal gravity waves, trapped around $1.8 \mathrm{~km}$ AGL (negative Scorer parameter; Fig. 9b). They impact CAPE and CIN and, in principle, could initiate convection.

Initially, CAPE peaked near the surface as well as between 1.5 and $2.0 \mathrm{~km}$ AGL (Fig. 14c). After the passage of the density current boundary, the CAPE became solely elevated with AERI-estimated MUCAPE values as high as $2000 \mathrm{~J} \mathrm{~kg}^{-1}$ above the density current head. This is more than twice the value observed about $1 \mathrm{~h}$ later by both the postboundary radiosonde and AERI (Fig. 12). At this level (about $1.5 \mathrm{~km} \mathrm{AGL),} \mathrm{CIN}$ vanished (Fig. 14d). It should be noted that AERI retrievals tend to estimate surface-based CAPE more accurately than elevated CAPE or CIN, on account of the decay of vertical resolution with height (Blumberg et al. 2017). The preboundary AERI profiles also reveal periods with zero CIN near the same level immediate CI. In reality, there must have been some CIN (in fact, the uncertainty in the AERI-derived 

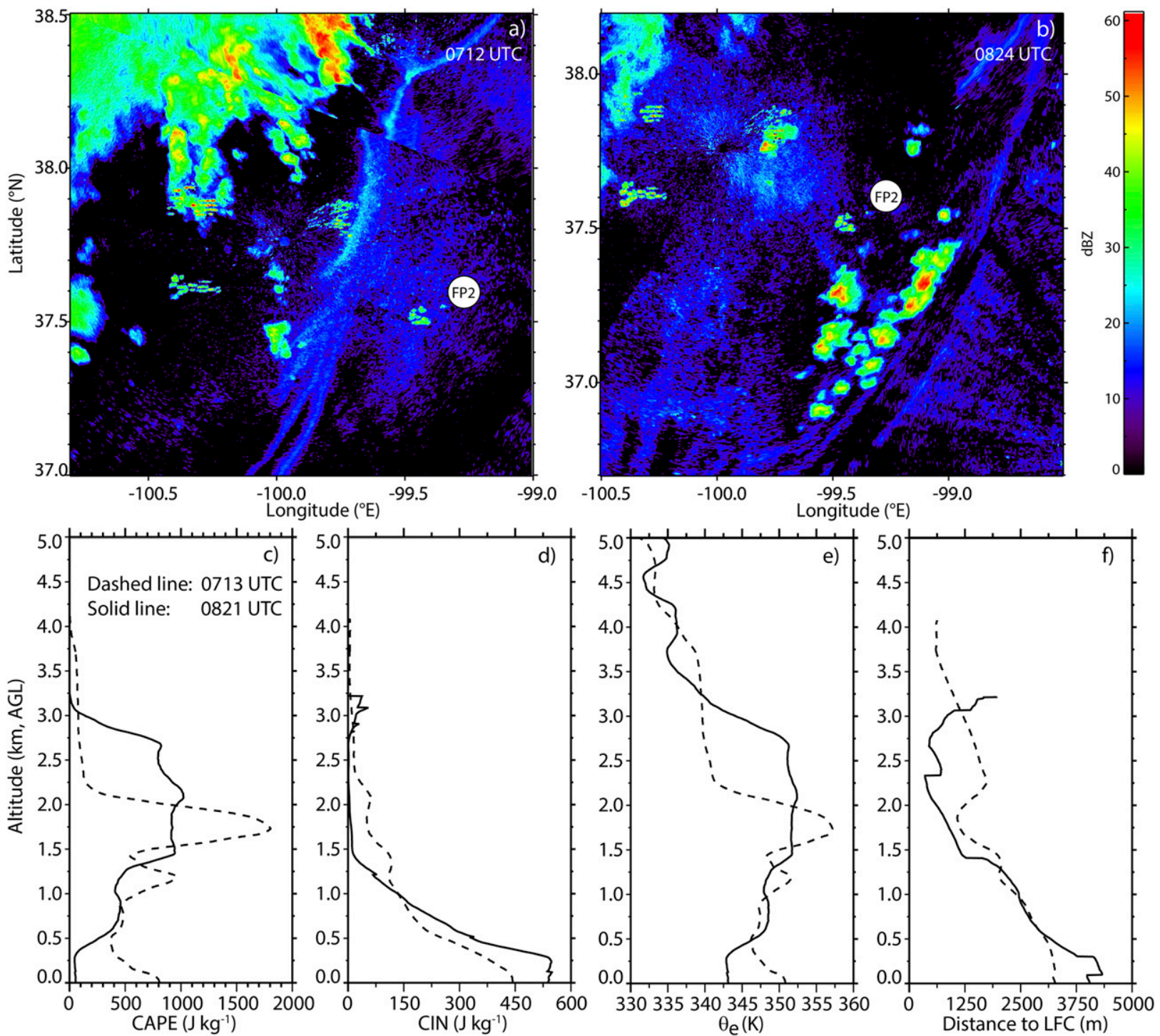

FIG. 13. As in Fig. 12, but for a bore passage over FP2

CIN when CIN is close to zero is about $30-50 \mathrm{~J} \mathrm{~kg}^{-1}$; Blumberg et al. 2017), and CI did not occur until sufficient layer lifting occurred.

The first and best defined of the three radar fine lines arrived at FP2 at 0736 (7.6) UTC (Fig. 15). At this point, the SBL was well developed, about $422 \mathrm{~m}$ deep (Table 2). Surface pressure and wind speed increased suddenly upon bore arrival, while the surface temperature increased slightly (Fig. 16). Yet, cooling occurred throughout the rest of the AERI profile (Fig. 15a), as is common with bores (Koch et al. 1991; Coleman and Knupp 2011). AERI water vapor profiles show moisture increased aloft with the passage of the bore, although less than the density current over FP5. Some gravity waves can be seen in the AERI data behind the leading boundary, most notable in $\theta_{v}$ contours, but they are of very low amplitude, compared with undular bores documented elsewhere (Knupp 2006; Koch et al. 2008a; Mueller et al. 2017). The ambient MUCAPE was much lower at FP2 than $5 \mathrm{~h}$ earlier at FP5, and CIN had become high near the surface on account of nocturnal cooling (Figs. 15c,d). CAPE peaked near $0.4 \mathrm{~km}$ AGL in the prebore environment, with large CIN. Substantial CAPE values (over $500 \mathrm{~J} \mathrm{~kg}^{-1}$ ) persisted only in small regions upon bore passage, but at higher levels $(\sim 1.0 \mathrm{~km}$ AGL) where the CIN was negligible. Thus, while the FP5 environment required very little lift for elevated CI to occur, releasing significant CAPE, the FP2 environment later at night required more lift and yielded less CAPE. Nevertheless, 

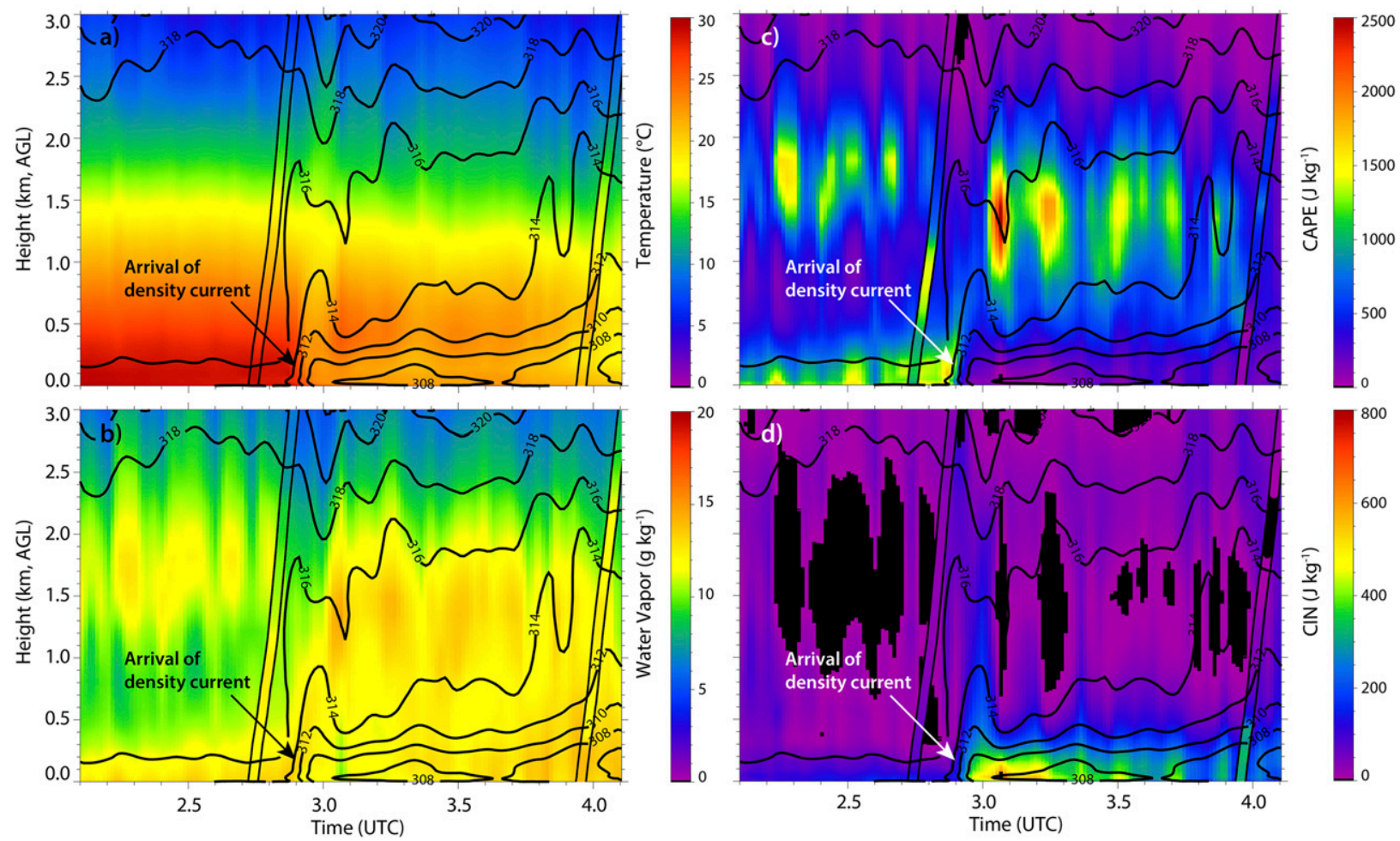

FIG. 14. AERI profiles capturing the DC passage at FP5. (a) Temperature, (b) water vapor, (c) CAPE, and (d) CIN. Contours are virtual potential temperature. The same data derived from two radiosondes are shown at their respective launch times between the two vertical lines; their slope accounts for the vertical velocity of the radiosonde.

it appears inconsequential whether the lift was due to a density current or a bore. In both cases, the lift was sufficient for (lagging) CI, but at FP5, this CI fed the developing MCS (Fig. 2), while at FP2 5 h later, the MCS was decaying and only isolated convective cells formed behind the boundary (Fig. 13b).

\section{Discussion}

Most atmospheric bores are observed in partially blocked flow regimes (e.g., Koch et al. 2008a; Haghi et al. 2017). According to hydraulic theory and laboratory experiments by Rottman and Simpson (1989), blocking within a two-layer system can have four different outcomes based on two parameters. The first parameter is the ratio of the depth of the density current $\left(d_{o}\right)$ to the depth of the lower, denser layer [i.e., the SBL depth $\left(h_{o}\right)$ ]. The second parameter is the Froude number, defined as the ratio of the speed of a density current to the speed of a gravity wave:

$$
\operatorname{Fr}=\frac{C_{\mathrm{dc}}}{C_{\mathrm{gw}}}=\frac{C_{\mathrm{dc}}}{\sqrt{g^{\prime} h_{o}}}
$$

Variable $C$ and subscripts dc and gw represent speeds of the density current and the gravity wave, respectively.
The depth ratio and Froude number determine whether the obstacle results in supercritical flow, partially blocked flow, complete blocking, or subcritical flow (Fig. 17).

The density current depth $d_{o}$ may be difficult to estimate from sounding data, but it can be estimated also from surface station data, assuming the pressure change across the boundary is hydrostatic and that density within the two air masses does not vary with height (Koch et al. 1991). We use virtual potential temperature $\theta_{v}$ in lieu of virtual temperature [which appeared in the original derivation in Koch et al. (1991)], as it is now common in similar calculations (Koch et al. 2008a,b; Mueller et al. 2017; Haghi et al. 2017):

$$
d_{o}=\frac{\theta_{v w} \Delta p}{\rho_{w} g\left(\frac{p_{c}}{p_{w}} \theta_{v w}-\theta_{v c}\right)} .
$$

Subscripts $w$ and $c$ represent measurements on the warm and cold side of the outflow boundary, respectively. To estimate the speed of the density current $\left(C_{\mathrm{dc}}\right)$ in Eq. (4), we use the fine line motion, as well as the following equation (Simpson 1987): 

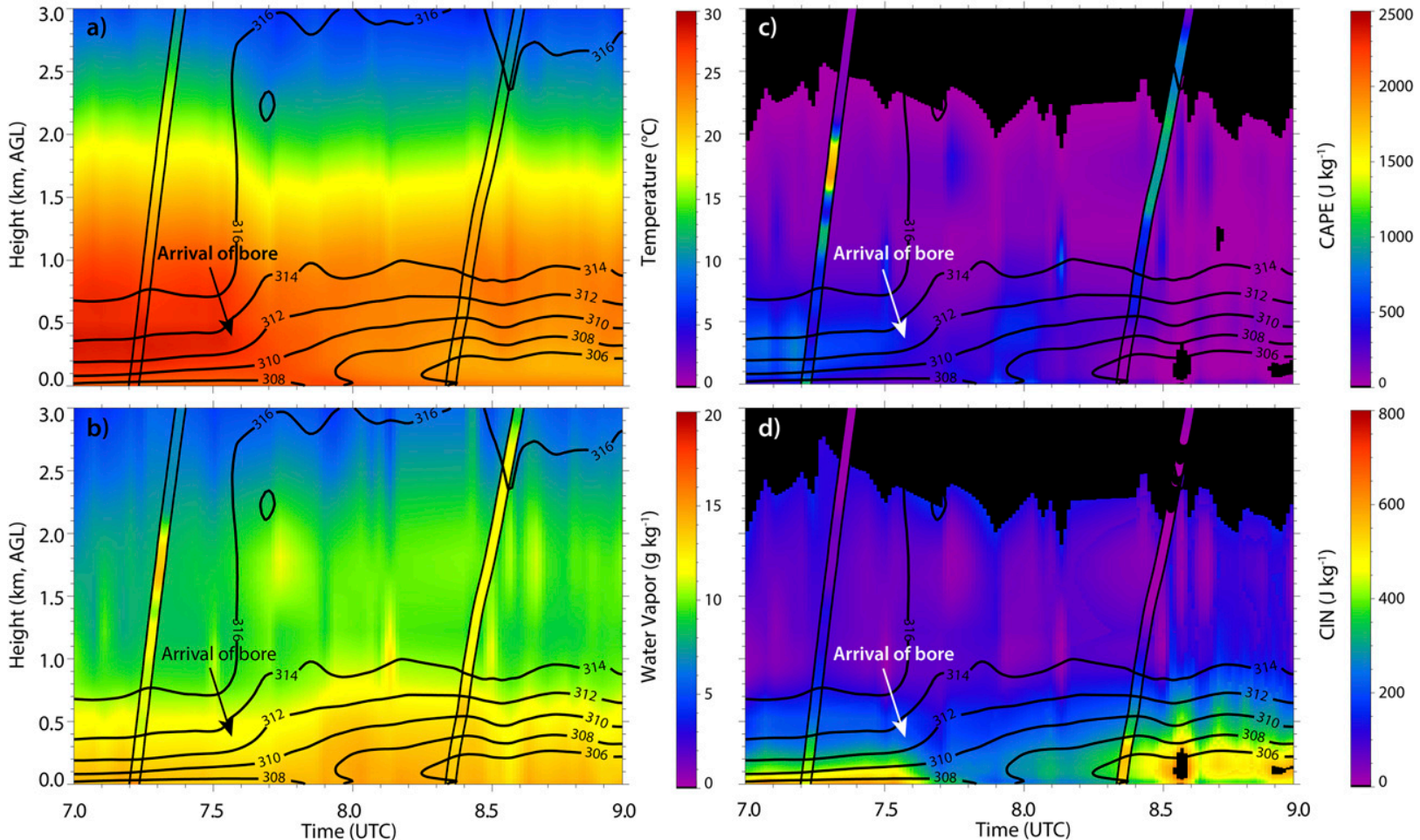

FIG. 15. As in Fig. 14, but for the bore passage at FP2.

$$
C_{\mathrm{dc}}=\sqrt{\frac{g \Delta T_{o}}{T_{c}}} .
$$

While the UWKA was completing transects in Region III, a nearby Kansas mesonet station at Ness City (KSRE) recorded surface conditions. During the density current passage, temperature at KSRE dropped $5.6 \mathrm{~K}$, and pressure rose $1.5 \mathrm{mb}$. The KSRE data yield a shallow density current $\left(d_{o}=580 \mathrm{~m}\right)$, and $C_{\mathrm{dc}}=10.4 \mathrm{~m} \mathrm{~s}^{-1}$. Using Eq. (4) with the gravity wave speed calculated from the radiosonde launched ahead of the outflow at $\mathrm{FP} 3, \mathrm{Fr}=2.1$. Furthermore, the CRL-inferred SBL depth $h_{o}$ is about $400 \mathrm{~m}$ (Fig. 10); thus, $d_{o} / h_{o}=1.45$. The Froude number and $d_{\delta} / h_{o}$ ratio indicate that the flow was partially blocked (see Table 2 and Fig. 17a). Observations from the UWKA in section $5 b$ and the partially blocked flow provide support that this was a bore preceded by a solitary wave.

Pairs of pre- and postboundary radiosondes are used to estimate flow regimes by plotting $d_{o} / h_{o}$ versus Fr. The nature of the flow is very sensitive to $d_{o} / h_{o}$ (Fig. 17). Here, we use both sounding- and surface-based [Eq. (5)] $d_{o}$ estimates where possible (Table 2). Figures $17 \mathrm{~b}$ and 17c show an example of a sounding-based approach: we define $d_{o}$ within the level of observed cooling where there is an increase in boundary-normal wind. AERI retrievals are also used to fine-tune the density current height estimate. It is important to note that since the density current penetrates into a stratified BL, cooling may occur above the top of the density current, making its depth more difficult to determine via the analysis of $\theta_{v}$ profiles only.

Boundaries with multiple radar fine lines are isolated in the bottom left of the flow regime diagram (Fig. 17a), within or near partially blocked flow. These smaller values of $d_{\delta} / h_{o}$ and Froude number from the southern side of the storm indicate an environment more conducive to partial blocking and bore formation. Boundaries identified as density currents (single radar fine line) are in environments conducive to intrusive or dissipative density current, as in the case of completely blocked flow, or unimpeded density currents within supercritical flow (Rottman and Simpson 1989).

As the night progressed and the SBL deepened, more of the outflow boundary transitioned from a density current to a bore. The vertical motion produced by bores and leading solitary waves contributed to the MCS even though the resulting CI was either lagging or cellular and separated from the main MCS precipitation. The observations presented herein suggest that bores, while they persist, may contribute to large vertical displacements that can initiate convection; however, they may 

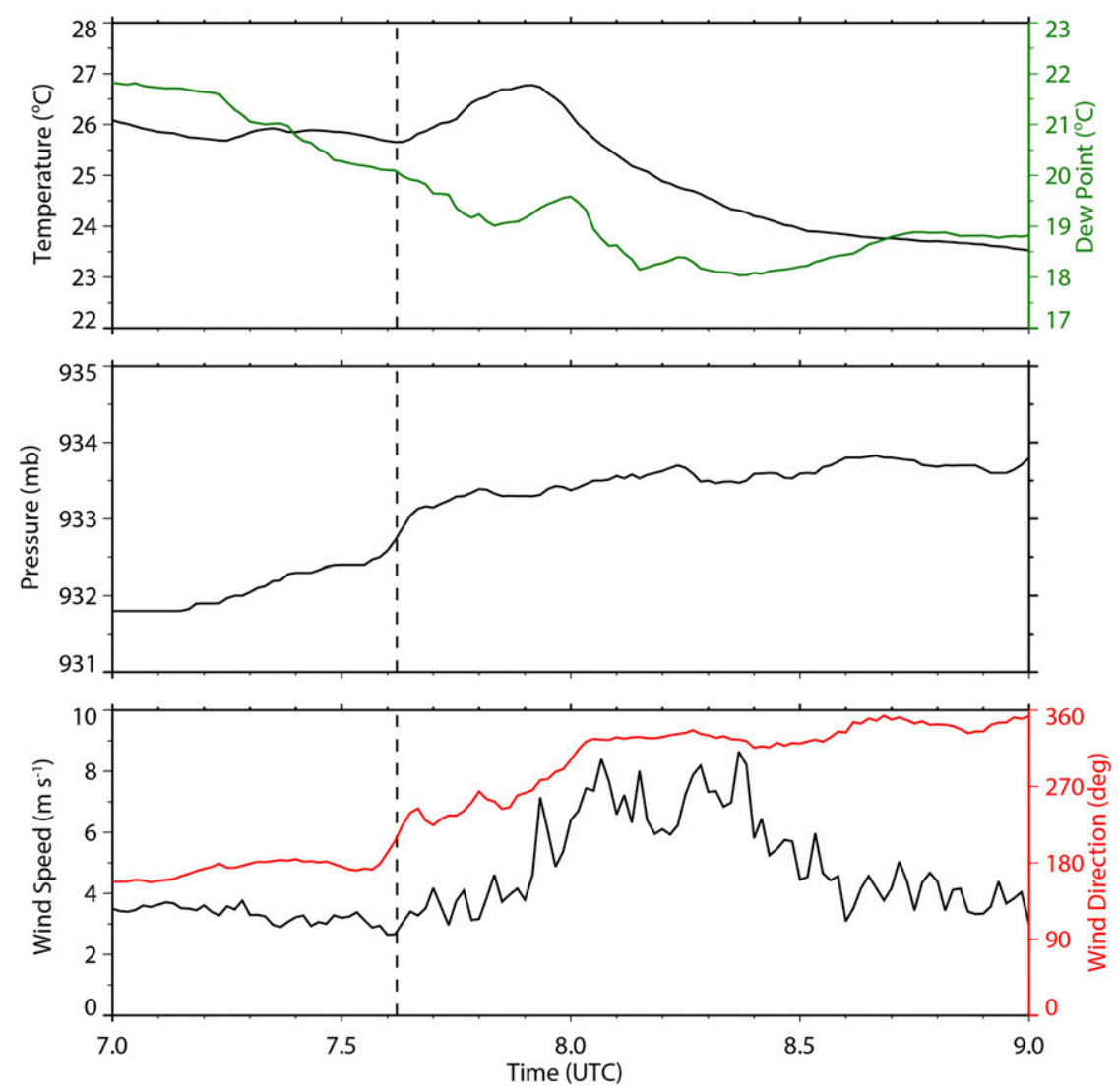

FIG. 16. Surface station data for FP2. The dashed line marks the arrival of the bore.

dissipate rapidly into multiple gravity waves that produce less vertical displacement (when compared to the parent density current). The UWKA observed smaller vertical displacements coincident with the leading solitary wave. Also, the southern bore and accompanying solitary waves propagated ahead of the main precipitation region and occasionally initiated cellular, short-lived convection that may have reduced MCS strength by consuming environmental CAPE and perturbing the boundary layer flow. As a result, the coherent precipitation area (i.e., the MCS) propagated more northward, where its strength was maintained by density currents that produced deeper lift and initiated immediate convection.

\section{Summary}

This study investigates outflow boundary-driven convection initiation maintaining a nocturnal MCS, observed on 15 July 2015 in western Kansas as part of PECAN. The MCS grew in intensity as it propagated eastward behind a well-developed outflow boundary that, depending on location and time, dynamically behaved as a density current or a bore. While areas of the outflow boundary existed as a classical density current that immediately initiated deep convection, other areas did not produce sufficient lift for immediate CI. In the latter areas, layers were lifted along a gentler slope to eventually reach their LFCs. Where convection lagged behind the convergent boundary zone, the profiling lidars onboard the UWKA and surface-based AERIs collected detailed observations of the type of boundary and its dynamics that displaced stably stratified air parcels. These are the main conclusions arising from this case study:

- The vertical displacement by both density currents and bores improves the likelihood for elevated CI by lifting and moistening layers above the SBL, but variation in their structures can necessitate the difference among immediate convection, lagged convection, and whether any ensuing convection joins and supports the MCS or remains isolated.

- Early in the night, or when conditions were not suitable for SBL blocking, the MCS outflow sustained a density current, whose depth was the main driver of CI. The 

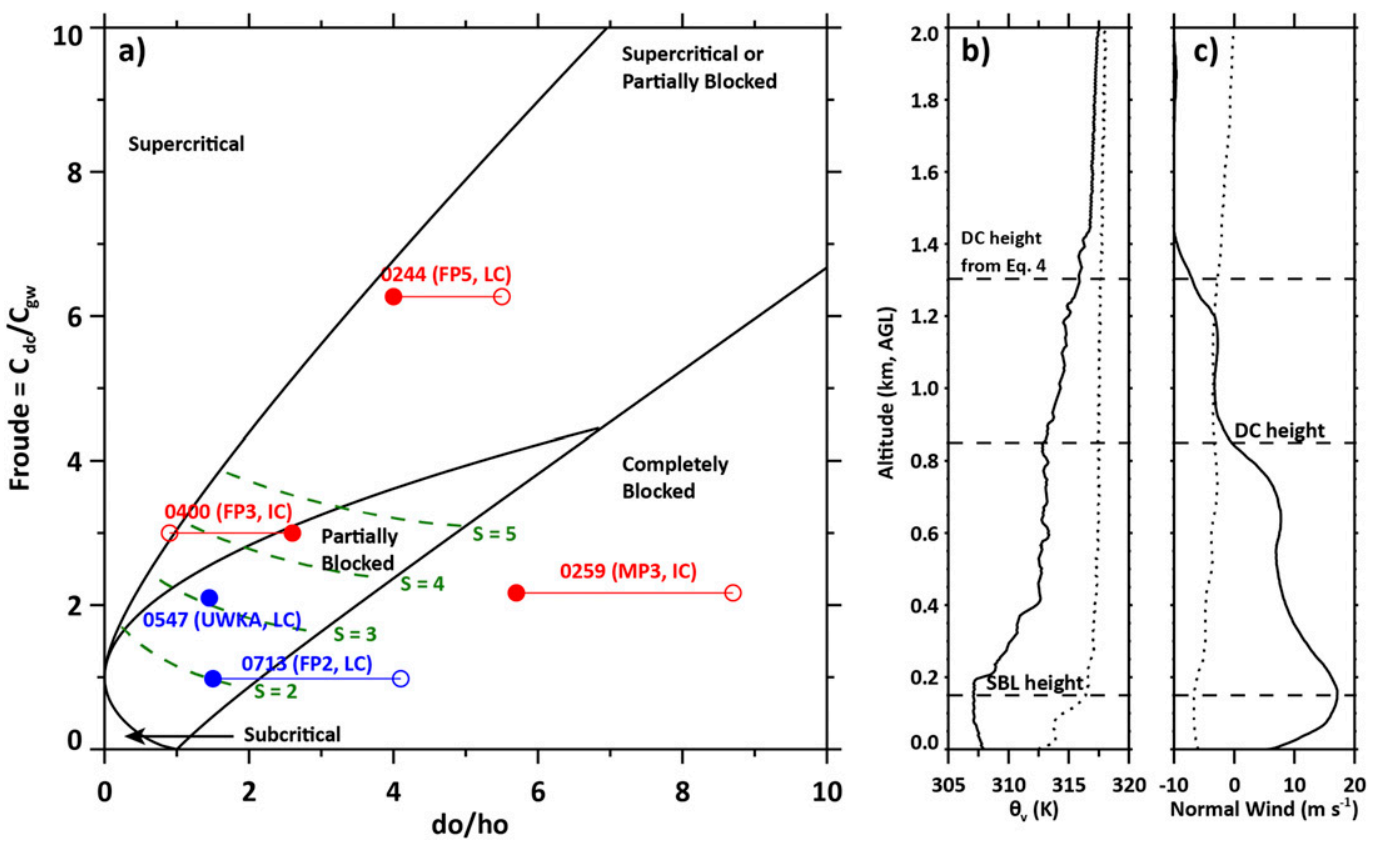

FIG. 17. (a) Flow regime upon DC collision with the SBL including time, location, and whether there was IC or LC. Blue (red) points indicate multiple (single) fine lines were observed on radar. Solid points used sounding and AERI data, while open points used Eq. (3) for DC depth. Theoretical bore strength ( $S=$ bore depth/SBL depth) is marked in green. Adapted from Rottman and Simpson (1989). (b),(c) Example of determining the DC height and SBL height from $\theta_{v}$ and boundary-normal wind from a radiosonde launched at MP3. Dotted lines are before DC passage, and solid lines are after passage.

ambient shear vorticity opposed the solenoidally generated vorticity, but was relatively weak. Where convection lagged behind the density current, the density current head was relatively shallow, but the cold pool gradually deepened behind the head so that displaced layers took longer to reach their LFCs. Outflow boundaries with multiple radar fine lines (indicative of bores) developed later in the night, as the SBL deepened and the LLJ developed.

- In addition to depth, bore evolution and propagation impacted elevated CI, which adds further complexity to its role in MCS maintenance. The UWKA observed vertical displacements up to $\sim 1 \mathrm{~km}$ that contributed to the MCS through lagged CI. However, where the bore strength was dissipating and more solitary waves were present, the bore propagated away from the MCS initiating cellular, short-lived convection. In this way, the evolving vertical structure of the bore (in conjunction with the environment) determined how the secondary CI affected the MCS evolution.

Acknowledgments. This study was funded by the National Science Foundation Grant AGS-1359645. The authors would also like to acknowledge Dana Mueller for initial data analysis and software development, Min Deng for her assistance with lidar data, and Rita Roberts for discussions and insight. PECAN data are archived by NCAR/EOL, which is funded by NSF.

\section{REFERENCES}

Blake, B. T., D. B. Parsons, K. R. Haghi, and S. G. Castleberry, 2017: The structure, evolution, and dynamics of a nocturnal convective system simulated using the WRF-ARW Model. Mon. Wea. Rev., 145, 3179-3201, https://doi.org/10.1175/ MWR-D-16-0360.1.

Blumberg, W. G., T. J. Wagner, D. D. Turner, and J. Correia Jr., 2017: Quantifying the accuracy and uncertainty of diurnal thermodynamic profiles and convection indices derived from the Atmospheric Emitted Radiance Interferometer. J. Appl. Meteor. Climatol., 56, 2747-2766, https://doi.org/10.1175/ JAMC-D-17-0036.1.

Bodine, D. J., and K. L. Rasmussen, 2017: Evolution of mesoscale convective system organizational structure and convective line propagation. Mon. Wea. Rev., 145, 3419-3440, https://doi.org/ 10.1175/MWR-D-16-0406.1.

Brown, E. N., C. A. Friehe, and D. H. Lenschow, 1983: The use of pressure fluctuations on the nose of an aircraft for measuring air motion. J. Climate Appl. Meteor., 22, 171-180, https://doi.org/ 10.1175/1520-0450(1983)022<0171:TUOPFO > 2.0.CO;2.

Carbone, R. E., and J. D. Tuttle, 2008: Rainfall occurrence in the U.S. warm season: The diurnal cycle. J. Climate, 21, 41324146, https://doi.org/10.1175/2008JCLI2275.1. 
,-- D. A. Ahijevych, and S. B. Trier, 2002: Inferences of predictability associated with warm season precipitation episodes. J. Atmos. Sci., 59, 2033-2056, https://doi.org/10.1175/ 1520-0469(2002)059<2033:IOPAWW>2.0.CO;2.

Caughey, S. J., and S. G. Palmer, 1979: Some aspects of turbulence structure through the depth of the convective boundary layer. Quart. J. Roy. Meteor. Soc., 105, 811-827, https://doi.org/ 10.1002/qj.49710544606.

Charba, J., 1974: Application of gravity current model to analysis of squall-line gust front. Mon. Wea. Rev., 102, 140-156, https:// doi.org/10.1175/1520-0493(1974)102<0140:AOGCMT>2.0.CO;2.

Christie, D. R., 1989: Long nonlinear waves in the lower atmosphere. J. Atmos. Sci., 46, 1462-1491, https://doi.org/10.1175/ 1520-0469(1989)046<1462:LNWITL>2.0.CO;2.

Clark, A. J., 2017: Generation of ensemble mean precipitation forecasts from convection-allowing ensembles. Wea. Forecasting, 32, 1569-1583, https://doi.org/10.1175/WAF-D-16-0199.1.

Clark, R., 2015: FP3 Millersville University surface meteorology and radiation data. Version 1.0. UCAR/NCAR-Earth Observing Laboratory, accessed 31 January 2018, https://doi.org/ 10.5065/D6CV4FTM.

_ 2016: FP3 Ellis, KS radiosonde data. Version 2.0. UCAR/ NCAR-Earth Observing Laboratory, accessed 11 January 2017, https://doi.org/10.5065/D6GM85DZ.

Coleman, T. A., and K. R. Knupp, 2011: Radiometer and profiler analysis of the effects of a bore and a solitary wave on the stability of the nocturnal boundary layer. Mon. Wea. Rev., 139, 211-223, https://doi.org/10.1175/2010MWR3376.1.

Colman, B. R., 1990: Thunderstorms above frontal surfaces in environments without positive CAPE. Part I: A climatology. Mon. Wea. Rev., 118, 1103-1122, https://doi.org/10.1175/15200493(1990)118<1103:TAFSIE > 2.0.CO;2.

Corfidi, S. F., 2003: Cold pools and MCS propagation: Forecasting the motion of downwind-developing MCSs. Wea. Forecasting, 18, 997-1017, https://doi.org/10.1175/1520-0434(2003)018<0997: CPAMPF $>2.0 . \mathrm{CO} ; 2$.

— S. J. Corfidi, and D. M. Schultz, 2008: Elevated convection and castellanus: Ambiguities, significance, and questions. Wea. Forecasting, 23, 1280-1303, https://doi.org/10.1175/2008WAF2222118.1.

Crook, N. A., 1988: Trapping of low-level internal gravity waves. J. Atmos. Sci., 45, 1533-1541, https://doi.org/10.1175/15200469(1988)045<1533:TOLLIG > 2.0.CO;2.

_- and M. W. Moncrieff, 1988: The effect of large-scale convergence on the generation and maintenance of deep moist convection. J. Atmos. Sci., 45, 3606-3624, https://doi.org/ 10.1175/1520-0469(1988)045<3606:TEOLSC > 2.0.CO;2.

Demoz, B. B., and Coauthors, 2005: The cold front of 15 April 1994 over the central United States. Part I: Observations. Mon. Wea. Rev., 133, 1525-1543, https://doi.org/10.1175/MWR2932.1.

Duda, J. D., X. Wang, F. Kong, and M. Xue, 2014: Using varied microphysics to account for uncertainty in warm-season QPF in a convection-allowing ensemble. Mon. Wea. Rev., 142, 2198-2219, https://doi.org/10.1175/MWR-D-13-00297.1.

Fovell, R. G., G. L. Mullendore, and S. Kim, 2006: Discrete propagation in numerically simulated nocturnal squall lines. Mon. Wea. Rev., 134, 3735-3752, https://doi.org/10.1175/MWR3268.1.

Fulton, R., D. S. Zrnić, and R. J. Doviak, 1990: Initiation of a solitary wave family in the demise of a nocturnal thunderstorm density current. J. Atmos. Sci., 47, 319-337, https://doi.org/ 10.1175/1520-0469(1990)047<0319:IOASWF>2.0.CO;2.

Geerts, B., and Coauthors, 2017: The 2015 Plains Elevated Convection at Night (PECAN) field project. Bull. Amer. Meteor. Soc., 98, 767-786, https://doi.org/10.1175/BAMS-D-15-00257.1.
Glickman, T. S., Ed., 2000: Glossary of Meteorology. 2nd ed. Amer. Meteor. Soc., 855 pp., http://glossary.ametsoc.org/.

Haghi, K. R., D. B. Parsons, and A. Shapiro, 2017: Bores observed during IHOP_2002: The relationship of bores to the nocturnal environment. Mon. Wea. Rev., 145, 3929-3946, https://doi.org/ 10.1175/MWR-D-16-0415.1.

Haimov, S., and A. Rodi, 2013: Fixed-antenna pointing-angle calibration of airborne Doppler cloud radar. J. Atmos. Oceanic Technol., 30, 2320-2335, https://doi.org/10.1175/JTECH-D12-00262.1.

Hartung, D. C., J. A. Otkin, J. E. Martin, and D. D. Turner, 2010: The life cycle of an undular bore and its interaction with a shallow, intense cold front. Mon. Wea. Rev., 138, 886-908, https://doi.org/10.1175/2009MWR3028.1.

Højstrup, J., 1982: Velocity spectra in the unstable planetary boundary layer. J. Atmos. Sci., 39, 2239-2248, https://doi.org/ 10.1175/1520-0469(1982)039<2239:VSITUP >2.0.CO;2.

James, R. P., P. M. Markowski, and J. M. Fritsch, 2006: Bow echo sensitivity to ambient moisture and cold pool strength. Mon. Wea. Rev., 134, 950-964, https://doi.org/10.1175/MWR3109.1.

Kaimal, J. C., J. C. Wyngaard, D. A. Haugen, O. R. Coté, Y. Izumi, S. J. Caughey, and C. J. Readings, 1976: Turbulence structure in the convective boundary layer. J. Atmos. Sci., 33, 2152-2169, https://doi.org/10.1175/1520-0469(1976)033<2152: TSITCB $>2.0 . \mathrm{CO} ; 2$.

Kingsmill, D., and N. A. Crook, 2003: An observational study of atmospheric bore formation from colliding density currents. Mon. Wea. Rev., 131, 2985-3002, https://doi.org/10.1175/15200493(2003)131<2985:AOSOAB >2.0.CO;2.

Klemp, J. B., R. Rotunno, and W. C. Skamarock, 1997: On the propagation of internal bores. J. Fluid Mech., 331, 81-106, https://doi.org/10.1017/S0022112096003710.

Knupp, K., 2006: Observational analysis of a gust front to bore to solitary wave transition within an evolving nocturnal boundary layer. J. Atmos. Sci., 63, 2016-2035, https://doi.org/10.1175/ JAS3731.1.

— 2015: Mobile PISA 2 UAH MIPS radiosonde data. Version 1.0. UCAR/NCAR-Earth Observing Laboratory, accessed 2 May 2017, https://doi.org/10.5065/D6MC8X3V.

Knuteson, R. O., and Coauthors, 2004: Atmospheric emitted radiance interferometer. Part II: Instrument performance. J. Atmos. Oceanic Technol., 21, 1777-1789, https://doi.org/ 10.1175/JTECH-1663.1.

Koch, S. E., and W. L. Clark, 1999: A nonclassical cold front observed during COPS-91: Frontal structure and the process of severe storm initiation. J. Atmos. Sci., 56, 2862-2890, https:// doi.org/10.1175/1520-0469(1999)056<2862:ANCFOD>2.0.CO;2. , P. B. Dorian, R. Ferrare, S. H. Melfi, W. C. Skillman, and D. Whiteman, 1991: Structure of an internal bore and dissipating gravity current as revealed by Raman lidar. Mon. Wea. Rev., 119, 857-887, https://doi.org/10.1175/1520-0493(1991) $119<0857:$ SOAIBA $>2.0$. CO 2 .

—, W. Feltz, F. Fabry, M. Pagowski, B. Geerts, K. M. Bedka, D. O. Miller, and J. W. Wilson, 2008a: Turbulent mixing processes in atmospheric bores and solitary waves deduced from profiling systems and numerical simulation. Mon. Wea. Rev., 136, 1373-1400, https://doi.org/10.1175/ 2007MWR2252.1.

_ C. Flamant, J. W. Wilson, B. M. Gentry, and B. D. Jamison, 2008b: An atmospheric soliton observed with Doppler radar, differential absorption lidar, and a molecular Doppler lidar. J. Atmos. Oceanic Technol., 25, 1267-1287, https://doi.org/ 10.1175/2007JTECHA951.1. 
Liu, B., Z. Wang, Y. Cai, P. Wechsler, W. Kuestner, M. Burkhart, and W. Welch, 2014: Compact airborne Raman lidar for profiling aerosol, water vapor and clouds. Opt. Express, 22, 20 613-20 621, https://doi.org/10.1364/OE.22.020613.

Liu, C., and M. W. Moncrieff, 2000: Simulated density currents in idealized stratified environments. Mon. Wea. Rev., 128, 1420-1437, https://doi.org/10.1175/1520-0493(2000)128<1420: SDCIIS $>2.0 . \mathrm{CO} ; 2$.

Locatelli, J. D., M. T. Stoelinga, P. V. Hobbs, and J. Johnson, 1998: Structure and evolution of an undular bore on the High Plains and its effects on migrating birds. Bull. Amer. Meteor. Soc., 79 , 1043-1060, https://doi.org/10.1175/1520-0477(1998)079<1043: SAEOAU $>2.0 . \mathrm{CO} ; 2$.

Maddox, R. A., 1980: Mesoscale convective complexes. Bull. Amer. Meteor. Soc., 61, 1374-1387.

Mahoney, W. P., 1988: Gust front characteristics and the kinematics associated with interacting thunderstorm outflows. Mon. Wea. Rev., 116, 1474-1492, https://doi.org/10.1175/15200493(1988)116<1474:GFCATK > 2.0.CO;2.

Markowski, P., and Y. Richardson, 2010: Mesoscale Meteorology in Midlatitudes. John Wiley \& Sons, 407 pp.

Marsham, J. H., S. B. Trier, T. M. Weckwerth, and J. W. Wilson, 2011: Observations of elevated convection initiation leading to a surface-based squall line during 13 June IHOP_2002. Mon. Wea. Rev., 139, 247-271, https://doi.org/10.1175/ 2010MWR3422.1.

Miao, Q., and B. Geerts, 2007: Finescale vertical structure and dynamics of some dryline boundaries observed in IHOP. Mon. Wea. Rev., 135, 4161-4184, https://doi.org/10.1175/ 2007MWR1982.1.

Morrison, H., G. Thompson, and V. Tatarskii, 2009: Impact of cloud microphysics on the development of trailing stratiform precipitation in a simulated squall line: Comparison of oneand two-moment schemes. Mon. Wea. Rev., 137, 991-1007, https://doi.org/10.1175/2008MWR2556.1.

Mueller, D., B. Geerts, Z. Wang, M. Deng, and C. Grasmick, 2017: Evolution and vertical structure of an undular bore observed on 20 June 2015 during PECAN. Mon. Wea. Rev., 145, 37753794, https://doi.org/10.1175/MWR-D-16-0305.1.

Paluch, I. R., and D. G. Baumgardner, 1989: Entrainment and fine-scale mixing in a continental convective cloud. J. Atmos. Sci., 46, 261-278, https://doi.org/10.1175/1520-0469(1989)046<0261: EAFSMI $>2.0 . \mathrm{CO} ; 2$.

Parker, M. D., 2008: Response of simulated squall lines to low-level cooling. J. Atmos. Sci., 65, 1323-1341, https://doi.org/10.1175/ 2007JAS2507.1.

Reif, D. W., and H. B. Bluestein, 2017: A 20-year climatology of nocturnal convection initiation over the central and southern Great Plains during the warm season. Mon. Wea. Rev., 145, 1615-1639, https://doi.org/10.1175/MWR-D-16-0340.1.

Rottman, J. W., and J. E. Simpson, 1989: The formation of internal bores in the atmosphere: A laboratory model. Quart. J. Roy. Meteor. Soc., 115, 941-963, https://doi.org/10.1002/ qj.49711548809.

Rotunno, R., J. B. Klemp, and M. L. Weisman, 1988: A theory for strong, long-lived squall lines. J. Atmos. Sci., 45, 463-485, https://doi.org/10.1175/1520-0469(1988)045<0463:ATFSLL> 2.0.CO;2.

Simpson, J. E., 1987: Gravity Currents in the Environment and the Laboratory. Ellis Horwood Limited, 244 pp.

Stensrud, D. J., J. W. Bao, and T. T. Warner, 2000: Using initial condition and model physics perturbations in short-range ensemble simulations of mesoscale convective systems. Mon
Wea. Rev., 128, 2077-2107, https://doi.org/10.1175/1520-0493 (2000)128<2077:UICAMP>2.0.CO;2.

Surcel, M., I. Zawadzki, M. K. Yau, M. Xue, and F. Kong, 2017: More on the scale dependence of the predictability of precipitation patterns: Extension to the 2009-13 CAPS Spring Experiment ensemble forecasts. Mon. Wea. Rev., 145, 36253646, https://doi.org/10.1175/MWR-D-16-0362.1.

Toms, B. A., J. M. Tomaszewski, D. D. Turner, and S. E. Koch, 2017: Analysis of a lower-tropospheric gravity wave train using direct and remote sensing measurement systems. Mon. Wea. Rev., 145, 2791-2812, https://doi.org/10.1175/MWR-D16-0216.1.

Turner, D. D., 2016a: FP2 AERIoe thermodynamic profile retrieval data. Version 1.0. UCAR/NCAR-Earth Observing Laboratory, accessed 12 December 2017, https://doi.org/ $10.5065 / \mathrm{d} 6 \times 63 \mathrm{k} 9 \mathrm{k}$.

- 2016b: FP3 AERIoe thermodynamic profile retrieval data. Version 2.0. UCAR/NCAR-Earth Observing Laboratory, accessed 23 February 2018, https://doi.org/10.5065/D6Z31WV0.

, 2016c: FP5 AERIoe thermodynamic profile retrieval data. Version 2.0. UCAR/NCAR-Earth Observing Laboratory, accessed 12 December 2017, https://doi.org/10.5065/d61v5c5j. and U. Löhnert, 2014: Information content and uncertainties in thermodynamic profiles and liquid cloud properties retrieved from the ground-based Atmospheric Emitted Radiance Interferometer (AERI). J. Appl. Meteor. Climatol., 53, 752-771, https://doi.org/10.1175/JAMC-D-13-0126.1.

UCAR/NCAR-Earth Observing Laboratory, 2016a: FP2 NPS surface flux data. Version 1.0. UCAR/NCAR-Earth Observing Laboratory, accessed 30 November 2017, https://data.eol.ucar.edu/ dataset/485.078

2016b: FP5 NCAR/EOL QC soundings. Version 2.0. UCAR/ NCAR-Earth Observing Laboratory, accessed 2 May 2017, https://doi.org/10.5065/D6ZG6QF7.

, 2016c: Radar regional 3D mosaic (realtime) in MDV format. Version 1.0. UCAR/NCAR-Earth Observing Laboratory, accessed 15 November 2017, https://doi.org/10.5065/D6BG2M6R. 2016d: FP3 FP4 FP5 QC 5 min surface data, tilt corrected. Version 1.0. UCAR/NCAR-Earth Observing Laboratory, accessed 10 November 2017, https://doi.org/10.5065/D6BZ645V.

University of Wyoming-Research Flight Center, 2017a: Flight level data from the University of Wyoming King Air during the Plains Elevated Convection at Night (PECAN) project. Version 1.0. University of Wyoming, College of Engineering, Department of Atmospheric Science, accessed 4 January 2018, https://doi.org/10.15786/M2901N.

, 2017b: Zenith pointing Wyoming Cloud Lidar (WCL) data from the University of Wyoming King Air during the Plains Elevated Convection at Night (PECAN) project. Version 1.0. University of Wyoming, College of Engineering, Department of Atmospheric Science, accessed 4 January 2018, https://doi.org/ 10.15786/M2588T.

Vermeesch, K., 2015: FP2 Greensburg, KS radiosonde data. Version 1.0. UCAR/NCAR-Earth Observing Laboratory, accessed 2 May 2017, https://doi.org/10.5065/D6FQ9TPH.

Wagner, T., E. Olson, N. Smith, and W. Feltz, 2016a: Mobile PISA 3 UW/SSEC SPARC radiosonde data. Version 2.0. UCAR/ NCAR-Earth Observing Laboratory, accessed 23 March 2017, https://doi.org/10.5065/D6VH5M7B.

,,,--- and $-2016 \mathrm{~b}$ : MP3 University of Wisconsin SPARC surface meteorological data. Version 1.0. UCAR/ NCAR-Earth Observing Laboratory, accessed 26 January 2017, https://doi.org/10.5065/D6N014XZ. 
,,--- , and $-2016 \mathrm{c}$ : MP3 University of Wisconsin SPARC AERIoe thermodynamic profile data. Version 1.0. UCAR/NCAR-Earth Observing Laboratory, accessed 24 March 2018, https://doi.org/10.5065/d60z71hc.

Wang, Z., P. Wechsler, W. Kuestner, J. French, A. Rodi, B. Glover, M. Burkhart, and D. Lukens, 2009: Wyoming Cloud Lidar: Instrument description and applications. Opt. Express, 17, 13 576-13 587, https://doi.org/10.1364/ OE.17.013576.

- and Coauthors, 2016: University of Wyoming King Air compact Raman lidar data. Version 1.0. UCAR/NCAR-Earth Observing Laboratory, accessed 4 January 2018, https:// doi.org/10.5065/d6ms3r0p.

Weckwerth, T. M., 2000: The effect of small-scale moisture variability on thunderstorm initiation. Mon. Wea. Rev., 128, 4017-4030, https://doi.org/10.1175/1520-0493(2000)129<4017:TEOSSM> 2.0.CO;2.

_, and R. M. Wakimoto, 1992: The initiation and organization of convective cells atop a cold-air outflow boundary. Mon.
Wea. Rev., 120, 2169-2187, https://doi.org/10.1175/1520-0493 (1992) $120<2169$ :TIAOOC $>2.0$. CO;2.

Weisman, M. L., and R. Rotunno, 2004: “A theory for strong longlived squall lines" revisited. J. Atmos. Sci., 61, 361-382, https:// doi.org/10.1175/1520-0469(2004)061<0361:ATFSLS >2.0.CO;2.

White, B. L., and K. R. Helfrich, 2014: A model for internal bores in continuous stratification. J. Fluid Mech., 761, 282-304, https://doi.org/10.1017/jfm.2014.599.

Wilson, J. W., and R. D. Roberts, 2006: Summary of convective storm initiation and evolution during IHOP: Observational and modeling perspective. Mon. Wea. Rev., 134, 23-47, https:// doi.org/10.1175/MWR3069.1.

Wu, D., and Coauthors, 2016: Airborne compact rotational Raman lidar for temperature measurement. Opt. Express, 24, A1210A1223, https://doi.org/10.1364/OE.24.0A1210.

Ziegler, C., M. Coniglio, M. Parker, and R. Schumacher, 2016: CSU/NCSU/NSSL MGAUS radiosonde data. Version 3.0. UCAR/NCAR-Earth Observing Laboratory, accessed 2 May 2017, https://doi.org/10.5065/D6W66HXN. 